San Jose State University

SJSU ScholarWorks

Master's Theses

Master's Theses and Graduate Research

Fall 2016

\title{
Estuarine Habitat Use by the California Sea Otter (Enhydra lutris nereis)
}

Jacqueline Kimberly Lindsey

San Jose State University

Follow this and additional works at: https://scholarworks.sjsu.edu/etd_theses

\section{Recommended Citation}

Lindsey, Jacqueline Kimberly, "Estuarine Habitat Use by the California Sea Otter (Enhydra lutris nereis)" (2016). Master's Theses. 4764.

DOI: https://doi.org/10.31979/etd.etd6-m44u

https://scholarworks.sjsu.edu/etd_theses/4764

This Thesis is brought to you for free and open access by the Master's Theses and Graduate Research at SJSU ScholarWorks. It has been accepted for inclusion in Master's Theses by an authorized administrator of SJSU ScholarWorks. For more information, please contact scholarworks@sjsu.edu. 


\title{
ESTUARINE HABITAT USE BY THE CALIFORNIA SEA OTTER (ENHYDRA LUTRIS NEREIS)
}

\author{
A Thesis \\ Presented to \\ The Faculty of the Moss Landing Marine Laboratories \\ San José State University
}

\author{
In Partial Fulfillment \\ of the Requirements for the Degree \\ Master of Science
}

by

Jacqueline Kimberly Lindsey

December 2016 
(c) 2016

Jacqueline Kimberly Lindsey

ALL RIGHTS RESERVED 
The Designated Thesis Committee Approves the Thesis Titled

ESTUARINE HABITAT USE BY THE CALIFORNIA SEA OTTER (ENHYDRA LUTRIS NEREIS)

by

Jacqueline Kimberly Lindsey

APPROVED FOR THE DEPARTMENT OF MARINE SCIENCE

SAN JOSÉ STATE UNIVERSITY

December 2016

James T. Harvey, Ph.D. Moss Landing Marine Laboratories

M. Tim Tinker, Ph.D. USGS/UC Santa Cruz

Scott Hamilton, Ph.D. Moss Landing Marine Laboratories 


\begin{abstract}
ESTUARINE HABITAT USE BY THE CALIFORNIA SEA OTTER (ENHYDRA LUTRIS NEREIS)

by Jacqueline Kimberly Lindsey
\end{abstract}

As the southern sea otter (Enhydra lutris nereis) range expands into northern and southern California, it will encounter estuaries that have been historically occupied by sea otters. Understanding how otters use re-colonized estuarine environments will inform how estuaries might be managed to encourage future sea otter range expansion. This project addressed the question: how do southern sea otters use space in the unique estuarine habitats of Elkhorn Slough? I compared the locations and behaviors of 25 individual sea otters of different status (male, female, and female with pup) among eelgrass, saltmud, saltmarsh, tidal creek, and main channel habitats in Elkhorn Slough. From these data I created a synoptic model to predict space use for resident otters of Elkhorn Slough based on sex, behavior, home range, and habitat distribution. Ninety percent home ranges calculated from the model indicated that females used larger home ranges than males in the slough, but both sexes had smaller home range areas than otters using the rocky outer-coast habitats of the Monterey Peninsula. In Elkhorn Slough, important habitats associated with resting included tidal creeks (for females only) and eelgrass, whereas the main channel was important for foraging behaviors of both sexes. Although using land habitats, sea otters were most likely to be found within $50 \mathrm{~m}$ of water. Protection of similar resting and foraging habitats in prey-rich estuaries colonized in the future will promote southern sea otters recovery by allowing them to re-colonize historically important estuarine habitats. 


\section{ACKNOWLEDGMENTS}

The work behind this thesis could not have been completed without the sea otter research community of California. Thank you for sharing your data and knowledge with me. I would also like to acknowledge the staff of USGS, UC Santa Cruz, the Monterey Bay Aquarium, CDFW, and the Elkhorn Slough National Research Reserve - in addition to the many interns and volunteers - who participated in Elkhorn Slough data collection. To Sarah Espinosa, an extra thank you for your moral support and many memorable days both in the field and in front of a laptop.

I am also grateful to the students of MLML who supported me through this project, in particular those in the Vertebrate Ecology Lab. Special thanks to my committee members for their guidance in this process and to all those who provided comments on early drafts.

Crucial funding for this thesis came from San Jose State University, The David and Lucile Packard Foundation, The American Cetacean Society: Monterey Bay Chapter, and MLML.

Finally, I'd like to thank my family for their love and support through graduate school. (When the going got tough, I blamed your early adoption of canvas bags!) Levi, I can't begin to express how grateful I am that you are always beside me. 


\section{TABLE OF CONTENTS}

LIST OF TABLES . . . . . . . . . . . . . . . . . vii

LIST OF FIGURES . . . . . . . . . . . . . . . . . viii INTRODUCTION 1

METHODS $\quad 5$

Study Site . . . . . . . . . . . . . . . . . . 5

Data Collection .......................... 5

Habitat Classification for Spatial Analysis . . . . . . . . . . . . . 10

Habitat Use Synoptic Model . . . . . . . . . . . . . . . . . . . . 11

Null Model of Individual Space-Use . . . . . . . . . . . . . . . . . . . 11

Home Range Area . . . . . . . . . . . . . . . . . . . . 14

$\begin{array}{ll}\text { RESULTS } & 15\end{array}$

Individual Home Ranges . . . . . . . . . . . . . . . . . . . . 15

Habitat Selection . . . . . . . . . . . . . . . 20

$\begin{array}{ll}\text { DISCUSSION } & 29\end{array}$

Individual Home Ranges . . . . . . . . . . . . . . . . . . . . . . 30

Habitat Selection . . . . . . . . . . . . . . . 32

$\begin{array}{ll}\text { REFERENCES } & 37\end{array}$ 


\section{LIST OF TABLES}

1 Habitat parameters and variable names. . . . . . . . . . . . . . 10

2 Percentage of males and females using between one and four centers of use.............................. 18

3 Difference in home range areas $\left(\mathrm{km}^{2}\right)$ for males, territorial males and females, calculated from the $90 \%$ isolpeth of the synoptic utilization distribution (two-sample $t(21.14)=-2.90, p=0.0085) . \ldots$ 


\section{LIST OF FIGURES}

1 Habitats within Elkhorn Slough, CA. Dates mark how far inland the majority of the sea otters could be found, by date of the following studies: 1983-4 (Kvitek et al. 1988), 1994-5 (Feinholz 1998), 1998-2003 (Kieckhefer et al. 2004) . . . . . . . . . . . . . . . . .

2 Histogram $($ bin $=5)$ of the number of resights recorded for each sea otter between October 2013 and May 2015. The dotted line indicates the natural break in number of resights. Animals with less than 75 resights were excluded from later analyses. . . . . . . . . . .

3 Number of resighted animals on each day of survey during the duration of the study. Number of otters resighted per day was between 1-30. Days without surveys (33) were not included. . . . . . . . . . .

4 Representative female (BRD1307 - top; BRD1291 - bottom) otters' centers of use from a two-dimensional kernel density analysis. Histograms reflect the relative density of points on the axis of latitude and longitude. Estimated density increases from dark to light colors in contour lines. . . . . . . . . . . . . . . . . . .

5 Representative male (BRD1313 - top; BRD1312 - bottom) otters' centers of use from a two-dimensional kernel density analysis. Histograms reflect the relative density of points on the axis of latitude and longitude. Estimated density increases from dark to light colors in contour lines. . . . . . . . . . . . . . . . . .

6 Representative female (BRD1291 - top) and male (BRD1312 - bottom) otters' centers of use from the $90 \%$ isopleth of the synoptic model's utilization distribution. Dark blue lines trace the $90 \%$ isopleth. . . . .

7 Distribution of female and male sea otters between the mouth of the slough and the furthest inland point (Distance from Ocean) and outwards from the main channel (Distance from Main Channel). Density decreases from yellow to blue. . . . . . . . . . . . . .

8 Predicted distribution for male sea otters in Elkhorn Slough, with high relative density indicated by warm magenta, and low relative density indicated by turquoise. . . . . . . . . . . . . . . 
9 Predicted distribution for female sea otters in Elkhorn Slough, with high relative density indicated by warm magenta, and low relative density indicated by turquoise. . . . . . . . . . . . . . . . .

10 Average effect of model parameters for male otters relative to the main channel (0) habitat. Parameters are significantly different when the 95\% CI does not include 0 . The model was run three times for all

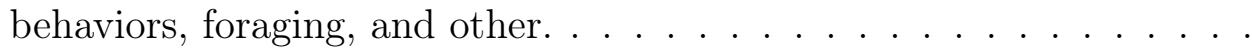

11 Average effect of model parameters for female otters relative to the main channel (0) habitat. Parameters are significantly different when the $95 \%$ CI does not include 0 . The model was run three times for all behaviors, foraging, and other. . . . . . . . . . . .

12 Average effect of model parameters for reproductive female otters relative to the main channel (0) habitat. Parameters are significantly different when the $95 \% \mathrm{CI}$ does not include 0 . The model was run two times for females with and without pups. . . . . . . . . . . .

13 Relative probability of use for saltmarsh and saltmud logit parameters, as a function of distance to water, for male and female otters. Sea otters used these land features less as their distance from water increased. . 


\section{INTRODUCTION}

Environmental factors associated with critical survival behaviors provide essential information about species ecology. Management decisions to improve the fitness of a threatened species are often based on habitat selection, or the tendency for an animal to use an area depending upon the resources contained within.

Restoring access to habitats where crucial foraging and resting behaviors occur can benefit individual fitness and increase population recovery. Defining habitat use, therefore, is therefore a focus for several current management efforts in California alone. Home ranges and habitat associations were recently calculated for the endangered island foxes (Urocyon littoralis santarosae) on the Channel Islands (Drake et al. 2015) to inform habitat restoration efforts. Mountain lion (Puma concolor) monitoring projects have relied upon landscape features to predict where the predators will consume their primary prey near developed areas (Benson et al. 2016). Understanding the association between behavior and habitat for the threatened southern sea otter (Enhydra lutris nereis) is similarly critical. Like island foxes and mountain lions, sea otters are easily tracked with tags, as they spend most of their time at the water's surface. The abundant location information that can be collected with a small group of trained observers makes sea otters an ideal species for evaluating context-dependent habitat use.

Throughout much of their range, sea otters perform a classic role as keystone predators (Estes and Duggins 1995). With a high metabolic rate and energetic requirements dictated by cold-water habitat (Costa 1982; Costa and Kooyman 1984), sea otters eat enough prey that their presence influences the entire ecosystem (U.S. Fish and Wildlife Service 2003). Unfortunately, the ecological importance of these top predators was not understood until after southern sea otters were hunted 
nearly to extinction for their pelts; by the beginning of the 20th century there were fewer than 100 individuals remaining along the Big Sur coastline (California Senate 1965).

Southern sea otters were designated in 1977 as a threatened subspecies under the Endangered Species Act. Recovering northern sea otter (Enhydra lutris kenyoni) populations have since expanded in number and range in Alaska, British Columbia, and Washington State, but southern sea otters have recovered more slowly in California. Although the carrying capacity for the California coastline is estimated at 15,000 animals (Laidre et al. 2001), the most recent southern population count was only 3,054 animals (USFW 2015). Comparisons between the two subspecies using the variables foraging time and prey quality have led to the realization that the California population is increasingly food limited, thus approaching carrying capacity in many areas (Estes et al. 1986; Estes 1990; Tinker et al. 2008a; Tinker et al. 2013; Thometz et al. 2016). Food limitation for female sea otters has restricted the amount of energy that can be transferred to dependent pups, and has led to increased mortality for pups and adults (Tinker et al. 2006). These mortalities have reduced population-level reproductive success (Thometz et al. 2014) within the existing range; however, there would be fewer mortalities if the range expanded into new territories with plentiful prey.

The southern sea otter's historical range extended from Baja California continuously along the west coast of California (USFW 2012). Within this extent there is archaeological evidence that indicates, prior to the fur trade, that otters were found not only along the outer coastline, but also within estuaries, like Elkhorn Slough (Woolfolk 2005; Jones et al. 2011). Due to the ease of capture in an estuary they were likely removed there completely; thus the remnant otter population at the end of the 1800s was located along the steep, wave exposed, rocky coast south of 
Monterey (California Senate 1965). Gradually, the range has increased to extend from Pigeon Point in the north to Point Conception in the south, but it was not until 1984 that otters re-colonized an estuary. The small resident otter population of Elkhorn Slough provided the first opportunity to examine sea otters within an estuary since the end of the fur trade.

Researchers conducting work in the lower reaches of Elkhorn Slough before 2010 documented the diet and foraging efforts of mostly male sea otters (Jolly 1997; Feinholz 1998; Wilkin 2003; Maldini et al. 2010). In 2003, Wilkin noted a diet of mostly crab (Cancer sp.), in addition to Washington clams (Saxidomus nuttallii) and fat inkeeper worms (Urechis caupo), but more recent researchers (Maldini et al. 2010) have noted a switch to a diet of mostly clams. This previous research in Elkhorn Slough dealt little with habitat association or home ranges. Although otters use estuary habitats, particularly in the winter in Alaska (USGS, unpublished data), no researchers have examined estuarine habitat use by sea otters. Despite decades of ecological research in Elkhorn Slough, neither the movement of otters among different habitats - particularly the upper reaches that were uninhabited until recently - nor a comparison of coastal and estuarine home ranges within this single geographic area, has been examined.

This project addressed the question: how do southern sea otters use space in the unique estuarine habitats of Elkhorn Slough? The objectives of this study were to compare behaviors of tagged sea otters in estuarine habitats, calculate habitat use and home ranges, and compare movements and habitats of sea otters in estuarine and outer-coast habitats.

Although we know little about sea otter use of estuaries, studies on sea otter use of the rocky outer coast of California have been in progress since the 1970s (Jameson 1989; Ralls et al. 1996). In early studies, observers found that the average 
home ranges of territorial male otters were smaller than non-territorial males and female otters due to the need to defend reproductive territories from encroaching males (Loughlin 1980; Jameson 1989; Ralls et al. 1996). They also found that sexual demographics drove males to travel long distances outside of their core home ranges (Jameson 1989; Ralls et al. 1996; Tinker et al. 2008b).

Hypothesis 1: In Elkhorn Slough home ranges of male and female sea otters will differ in size, with territorial male home ranges being smaller in area and spread non-continuously over a greater range than female and non-territorial sea otters.

Otter behaviors on the outer coast also were affected by habitat availability, in particular the availability of kelp to provide shelter from open ocean waves (Jameson 1989; Ralls et al. 1996). Using activity budgets, researchers documented that otters moved into these sheltered areas before resting, but performed active foraging during periods of greater wind when shelter was harder to find (Estes et al. 1986).

Hypothesis 2: Context-dependent habitat use by individuals in the estuary can be used to predict habitat use by groups of sea otters Hypothesis 3: Context-dependent habitat use in the estuary will include sheltered habitats associated with resting and less-sheltered main channel habitats associated with foraging.

I compared 25 individual otters of different status (male, female, female with pup) among different habitats in Elkhorn Slough to evaluate home range and context-dependent habitat use in sea otters living within an estuarine environment. 


\section{METHODS}

\section{Study Site}

Elkhorn Slough is a seasonal estuary and tidal embayment located within the Monterey Bay (Caffrey and Broenkow 2002). Because of the sheltered nature of the estuary and the abundance of soft-sediment foraging habitat (Feinholz 1998), Elkhorn Slough is used by an increasing number of sea otters. It was occupied first by a seasonal raft of otters in the 1980s (Kvitek et al. 1988), and later by females with pups starting in 2000 (USGS, unpublished data). Use of the slough by sea otters has progressed incrementally inland from the harbor, advancing from the harbor mouth (Kvitek et al. 1988), through the open channel beyond the first protected curve (Feinholz 1998), and into the marsh and mud-covered tidal inlets of the slough's upper reaches (Kieckhefer et al. 2004) (Fig. 1) at an average of $0.2 \mathrm{~km}$ per year. This shift has been accompanied by a shift in diet (Wilkin 2003; Maldini et al. 2010), possibly indicating prey depletion (Jolly 1997). Elkhorn Slough's resident otter population during this study was around 100 otters, or $3 \%$ of the southern sea otter population.

Habitats vary along the length and width of Elkhorn Slough (Fig. 1). Eelgrass grows from the bottom of the main channel, and is visible from the surface at lower tides. Saltmarsh is vegetation on land that is visible above the high tide line and is regularly flooded and drained of seawater. Saltmud habitat is formed by the sediment that is fully covered at high tide, but revealed on lower tides. The main

channel follows the flow of the slough $11 \mathrm{~km}$ inland, but some water branches into tidal creeks (Fig. 1).

\section{Data Collection}

To allow for longitudinal data collection on individual habitat use, in September 2013, 20 sea otters in Elkhorn Slough were captured and tagged with 


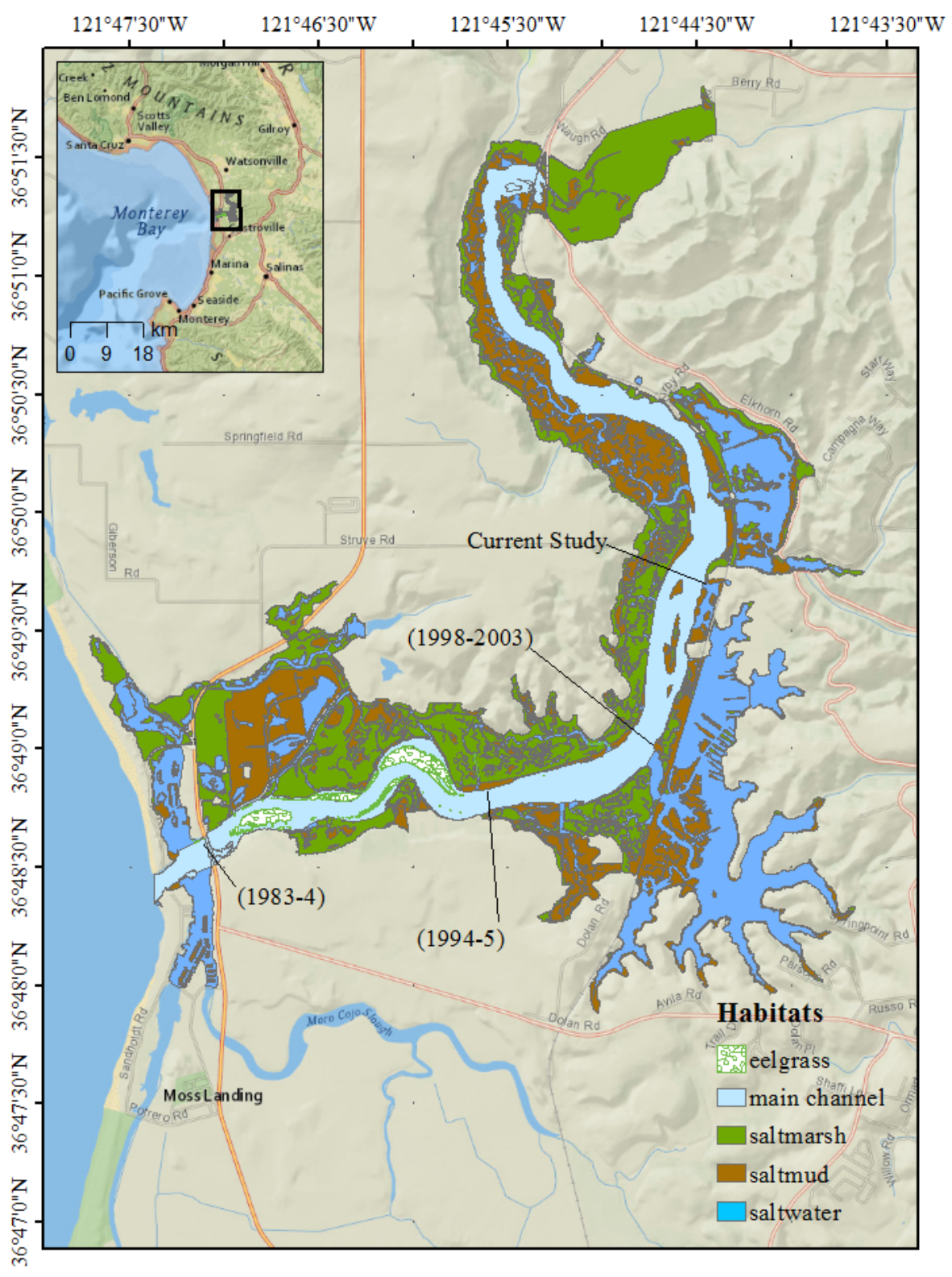

Fig. 1. Habitats within Elkhorn Slough, CA. Dates mark how far inland the majority of the sea otters could be found, by date of the following studies: 1983-4 (Kvitek et al. 1988), 1994-5 (Feinholz 1998), 1998-2003 (Kieckhefer et al. 2004)

flipper (livestock ear tags, Temple, TX) and VHF transmitting tags $(80 \mathrm{x} 22 \mathrm{x}$ $50 \mathrm{~mm}, 160 \mathrm{~g}$, Advanced Telemetry Systems, Isanti, MN) according to previously published methodologies (Ralls et al. 1989; Tinker et al. 2006). Each sea otter was 
opportunistically net captured by experienced biologists, and placed in a cooled box for transport to the mobile veterinary station. On land, veterinary technicians prepared each otter for an approximately 45-minute surgery, administering general anesthesia and sampling for parallel studies (USGS, unpublished data). Within two hours, each sea otter had completed tag implantation surgery and was returned to a fresh transport box. Otters were released to the areas where they were captured and monitored for abnormal behavior. A second round of captures occurred in April 2015 where eight more animals were acquired for the study. These efforts were part of a three-year population study led by U.S. Geological Survey (USGS) and the University of California Santa Cruz (UCSC) in collaboration with the Monterey Bay Aquarium (MBA), Elkhorn Slough National Estuarine Research Reserve (ESNERR), and California Department of Fish and Wildlife (CDFW). Captures, handling, tagging, and sampling were conducted under a Federal research permit (MA672624-18) issued to M.T. Tinker and under SJSU/UCSC IACUC approval (protocols Harvey/Lindsey 999, Tinkert 1306).

Following sea otter release, trained observers conducted five-hour shifts every day traveling through Elkhorn Slough and locating as many of the study animals as they could find. Tagged sea otters were located using a VHF (30-300 MHz) antenna and receiver (Advanced Telemetry Systems, Isanti, MN) tuned to the tags' transmitting frequencies, and were observed using a spotting scope (Questar Corp., New Hope, PA). For each sighting of a tagged sea otter, observers recorded the global positioning system (GPS) location, weather conditions, instantaneous behavior of the targeted otters (foraging, resting, grooming, grooming pup, interacting, hauled out, etc.), and activity level (active or inactive). Volunteers and staff members from USGS, UCSC, and the Monterey Bay Aquarium Sea Otter Research and Conservation (SORAC) program assisted in data collection, allowing 
the potential for daily resights of tagged otters. For the following analyses, I used data collected from the first 19 months of the observation study. Twenty animals from the 2013 captures and five from the 2015 captures met criteria of at least 75 resights to be used in habitat analyses. This criterion was set at a natural break in the number of resights for each animal (Fig. 2), maximizing the number of individuals while retaining enough resight points to run the following analyses.

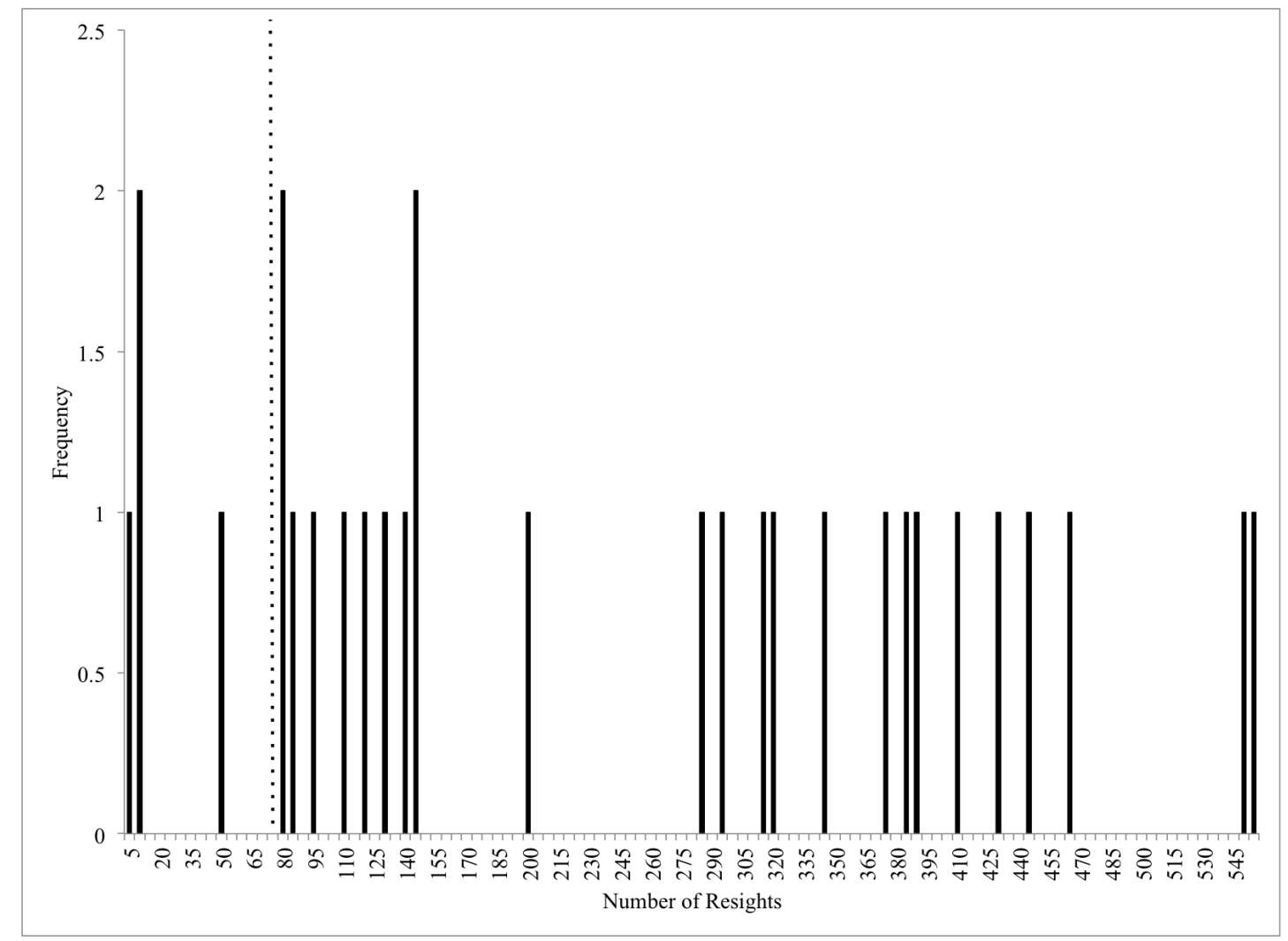

Fig. 2. Histogram $($ bin $=5)$ of the number of resights recorded for each sea otter between October 2013 and May 2015. The dotted line indicates the natural break in number of resights. Animals with less than 75 resights were excluded from later analyses.

\section{Overview of Home Range and Habitat Analysis}

The resight location data were used to analyze habitat use in Elkhorn Slough with a synoptic model, which was based on work by Horne and colleagues (2008). 
The synoptic space-use model was developed to simultaneously estimate an animal's probability of occurrence as a function of the animal's centralizing home range tendencies and the spatial distribution of resources. The model started with a null model of utilization probability created without any habitat variables, and was built by testing if habitat covariates added to the predictive ability of the null model to describe space use. Individual habitat preferences were then included as random effects nested within groups. To account for resights clustered in multiple centers of use, the null model of space use was created with a 2-dimensional kernel density surface. Rather than parameterizing the model with maximum likelihood (Horne et al. 2008), a Bayesian hierarchical model was used to calculate a probability of utilization for different groups of sea otters (Equation 1). The key equation of the synoptic model predicted the relative probability $s$ of finding otter $o$ at spatial location $x_{i}$.

$$
s_{o}\left(x_{i}\right)=\frac{f_{0, o}\left(x_{i}\right) \prod_{j=1}^{J}\left(1+\beta_{j, o} \cdot H_{j}\left(x_{i}\right)\right)}{\int f_{0, o}\left(x_{i}\right) \prod_{j=1}^{J}\left(1+\beta_{j, o} \cdot H_{j}\left(x_{i}\right)\right)}
$$

where $f_{0, o}$ is the probability of otter $o$ occurrence at $x_{i}$ based on the null model, $\beta_{j, o}$ is a selection parameter that determines how much an individual $i$ selects for or against each habitat variable $j$, and $H_{j}$ is a categorical variable for each habitat type that is set to 1 if habitat type $j$ occurs at point $x_{i}$ but otherwise is set to 0 .

The synoptic space-use model created a utilization probability surface for each study animal, from which a $90 \%$ utilization polygon, or home range, was calculated. Because of the complex shape of the available habitat in Elkhorn Slough, traditional estimations of home range - like kernel density analysis - were not ideal; they included land and hills between centers of use, where sea otters were not actually found. By including habitat within the home-range estimation, the synoptic space-use model created a two-dimensional home range utilization surface for each 
animal that allowed for multiple centers of use and avoided high probabilities of utilization in habitats where otters did not occur. In addition, the hierarchical analysis of this model eliminated the need to manually compare each home range with habitat locations to identify key habitats.

\section{Habitat Classification for Spatial Analysis}

To test hypotheses related to the use of different habitats, GPS locations were layered with geographic information system (GIS) habitat data for the Elkhorn Slough (Fig. 1). The habitat data were compiled from previous surveys by the Elkhorn Slough National Estuarine Research Reserve, and included maps of eelgrass and shoreline habitat. Finally, the water habitat was divided into main channel and tidal creek areas.

To sample these habitat data for modeling, a grid of $20 \mathrm{~m}$ x $20 \mathrm{~m}$ cells was created overlaying the map of Elkhorn Slough. Each of these grid points $\left(x_{i}\right)$ was classified with at least one habitat type $\left(H_{j}\left(x_{i}\right)\right)$ from Table 1 . In addition, distance to water polygons, distance to the main channel, and distance from the mouth of the estuary was determined at each grid point. Distance from the mouth was calculated along a polyline drawn inland along the path of Elkhorn Slough. Grid points were then spatially joined to each sea otter resight for all individual otters to indicate how many resights were present at each grid point $\left(x_{i}\right)$.

Table 1. Habitat parameters and variable names.

\begin{tabular}{ll}
\hline \multicolumn{1}{c}{ Habitat $j$} & Variable Name $H_{j}$ \\
\hline main channel & reference level \\
eelgrass & $H_{\text {eelgrass }}$ \\
saltmarsh & $H_{\text {saltmarsh }}$ \\
saltmud & $H_{\text {saltmud }}$ \\
tidal creek & $H_{\text {creek }}$ \\
\hline
\end{tabular}




\section{Habitat Use Synoptic Model}

\section{Null Model of Individual Space-Use}

Null centers of use $f_{0, o}\left(x_{i}\right)$ for each sea otter were calculated using a two-dimensional kernel density analysis in Matlab (MathWorks, Natik, MA) using location points collected from resights. The kernel density bandwidth (or smoothing kernel) was set at $150 \mathrm{~m}$ x $150 \mathrm{~m}$; this value was selected based on expert opinion, as larger bins hid features of the complex landscape whereas smaller bins tended towards overfitting. The output of this analysis provided an general distribution of space use by otters, without considering habitat parameters. To speed processing, grid cells with no resights - therefore, negligible probabilities - were removed from further analysis until the final probabilities were calculated.

\section{Synoptic Space-Use Model}

The smoothed kernel density map for each otter's centers of use served as the null probability surface $\left(f_{0, o}\right)$ for the synoptic model (Equation 1$)$. I built upon the null distribution within the synoptic model using variables that represent habitat designations $\left(H_{j}\right)$. For the purposes of the categorical habitat selection parameters in the synoptic model, main channel habitat was the reference level to which all other habitats were compared. Habitat selection parameters were then fit for other habitat types relative to the main channel: salt water in tidal creeks, eelgrass, saltmarsh, and saltmud. In the case of saltmarsh and saltmud habitats, I also included continuous parameters to account for the effect of distance to open water. The numerator of Equation 1 was adjusted as follows:

$$
\begin{array}{r}
s_{o}\left(x_{i}\right)=f_{0, o}\left(x_{i}\right) \cdot\left(1+\beta_{\text {creek }, o} \cdot H_{\text {creek }}\left(x_{i}\right)\right) \cdot\left(1+\beta_{\text {eelgrass }, o} \cdot H_{\text {eelgrass }}\left(x_{i}\right)\right) \\
\left(1+\beta_{\text {saltmarsh }, o} \cdot H_{\text {saltmarsh }}\left(x_{i}\right)\right) \cdot\left(1+\beta_{\text {saltmud,o },} \cdot H_{\text {saltmud }}\left(x_{i}\right)\right) \cdot \\
\left(1+f_{\text {distmarsh }, o} \cdot H_{\text {saltmarsh }}\left(x_{i}\right)\right) \cdot\left(1+f_{\text {distmud }, o} \cdot H_{\text {saltmud }}\left(x_{i}\right)\right)
\end{array}
$$


where

$$
\begin{aligned}
f_{\text {distmarsh }, o} & =-1+\operatorname{logit}^{-1}\left(\beta_{\text {Dsaltmarsh }, o} \cdot \frac{\text { dist.water }\left(x_{i}\right)}{200}+5\right) \\
f_{\text {distmud }, o} & =-1+\operatorname{logit}^{-1}\left(\beta_{\text {Dsaltmud }, o} \cdot \frac{\text { dist.water }\left(x_{i}\right)}{200}+5\right)
\end{aligned}
$$

The last two parameters in Equation 2 depend on parameters estimated with log function weighting. These logit parameters were used to weight saltmarsh and saltmud parameters by their distance to water. Logit parameters were chosen because sea otters were found on land features within a certain distance of water, but the probability of sighting an otter quickly decreased further from water. I used these logit parameters from the converged model to determine the range of distances from water where sea otters can be found.

Fitted selection parameters $\left(\beta_{j, o}\right)$ were used to weight habitat variables $\left(H_{j}\right)$ more heavily when otters were frequently found within the habitat. The parameters were fitted for an overall category of sea otters (for example, adult males), and then individual parameters were drawn from within the distribution produced by the group as a whole. For each $\beta$ parameter, the following uninformative prior distributions were used:

$$
\begin{aligned}
\beta_{j, o} & \sim \operatorname{Normal}\left(\beta_{j}, \tau_{j}\right), \beta_{j, o} \geq-1 & \beta_{D j, o} & \sim \operatorname{Normal}\left(\beta_{D j}, \tau_{D j}\right),-30 \leq \beta_{D j, o} \leq 0 \\
\beta_{j} & \sim \operatorname{Gamma}(1.1,1)-1 & & \beta_{D j} \sim-1 \cdot \operatorname{Normal}(10,0.01),-30 \leq \beta_{D j} \leq 0 \\
\tau_{j} & \sim \operatorname{Gamma}(1.5,1) & \tau_{D j} & \sim \operatorname{Gamma}(1.5,0.1)
\end{aligned}
$$

where $\tau_{j}$ is a fitted parameter that specifies the amount of individual variation for each hierarchical parameter. The variance $(\tau)$ for the $\beta_{j, o}$ parameter was less if the group as a whole had the same distribution among habitat types.

Selection parameters $\left(\beta_{j, o}\right)$ were fit within the model by iterating through grid points $\left(x_{i}\right)$ with the number of individual resights at each grid point $x_{i}$ treated as an 
observed random node drawn from a negative binomial distribution with mean probability $s_{o}\left(x_{i}\right)$. (Note that the negative binomial was used instead of the poisson distribution to account for over dispersion of resights; the over dispersion parameter itself was treated as another fitted parameter.) The probability of a sea otter being in a given location $\left(s_{o}\left(x_{i}\right)\right)$ was the result of the product of the null kernel density model $\left(f_{0, i}\right)$, the individual weights $\left(1+\beta_{o, j}\right)$ for each parameter $H_{j}$, and a distance logit parameter for saltmud and saltmarsh habitat parameters.

Equations were solved for each animal using Matlab ${ }^{\circledR}$ software, JAGS (Just Another Gibbs Sampler), and the matjags interface to run a Markov Chain Monte Carlo (MCMC) sampled Bayesian inference. I ran four chains in parallel, each with a 500-sample burn-in phase and 5000 samples recorded. Eight sub-groups of sea otters were run separately to compare the weighting of the $\beta_{j, o}$ selection parameters; these groups included males, females, females with pups, and females without pups, which were further divided by behavior into groups of 'foraging' and 'other'. Using the model-estimated values of $s_{o}\left(x_{i}\right)$, I created maps depicting areas of greater use for the slough as a whole and for each sea otter category.

Habitat parameters that were excluded from the model included the distance from the main channel and the distance from the ocean; these two parameters were rendered irrelevant by the kernel density analysis, which served as the null distribution $f_{0, o}$ for individuals in the synoptic model. However, when the model was used to predict space use for groups of sea otters, rather than for individuals, the excluded parameters were used as a stand-in for individual kernel density distributions. To accomplish this, a general kernel density model was fit to the distance from ocean and distance from main channel parameters for all animals. Without this post-fitting weight, the output of the model would determine which locations and habitat types were possible throughout the entire length of the slough. 
I included the distance from the main channel and distance from the slough mouth in the post-fitting model to demonstrate predicted areas of use at the time of the model's creation.

\section{Home Range Area}

In order to quantitatively compare home ranges between otters and groups of otters, I calculated home range areas from the $s_{o}\left(x_{i}\right)$ probability surface. The utilization distributions were converted into home range estimates by drawing a $90 \%$ isopleth polygon and calculating the area in $\mathrm{km}^{2}$. These areas were averaged for male, territorial male, and female otters; males groups were compared to females with a two-sample t-test. Individual home range estimates were also tested for linear correlation with otter size and average group density (average number of otters surrounding the target otter at each resight point). 


\section{RESULTS}

During the 19 months of data collection, the average number of resights collected each day was 9.9, with a maximum of 30 animals on a single day (Fig. 3). Twenty-five individuals fit my selection criterion of over 75 resights during the two years, including 16 females and 9 males.

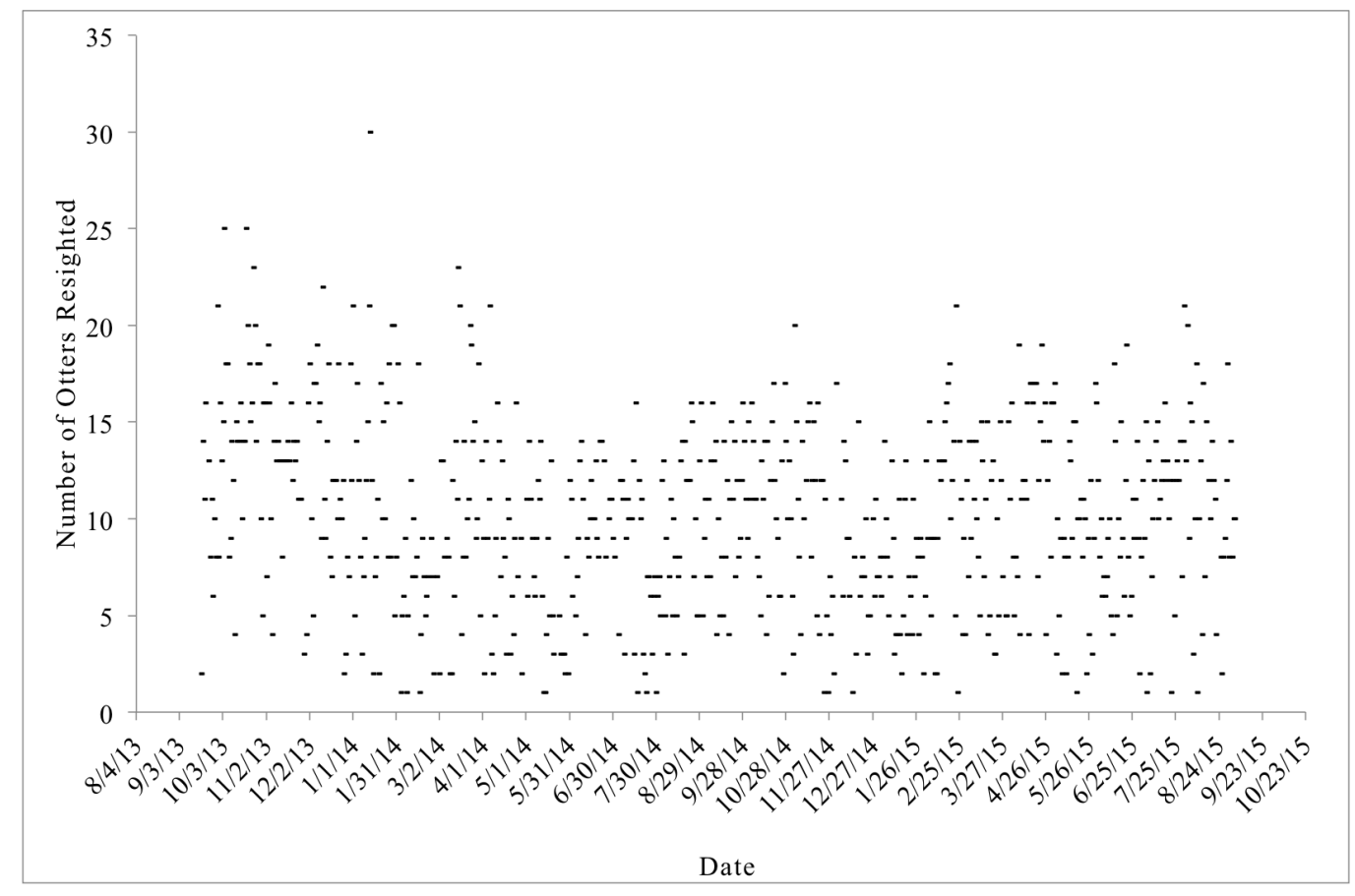

Fig. 3. Number of resighted animals on each day of survey during the duration of the study. Number of otters resighted per day was between 1-30. Days without surveys (33) were not included.

\section{Individual Home Ranges}

To determine the null distribution of individual space use, two-dimensional kernel densities of the 25 sea otters were calculated individually (Fig. 4, 5).

Individuals varied within each sex in both number and distribution of centers of use. Kernel density analysis (Fig. 4, 5) indicated that male otters had one to three centers of use, whereas females had between one and four (Table 2). The median 

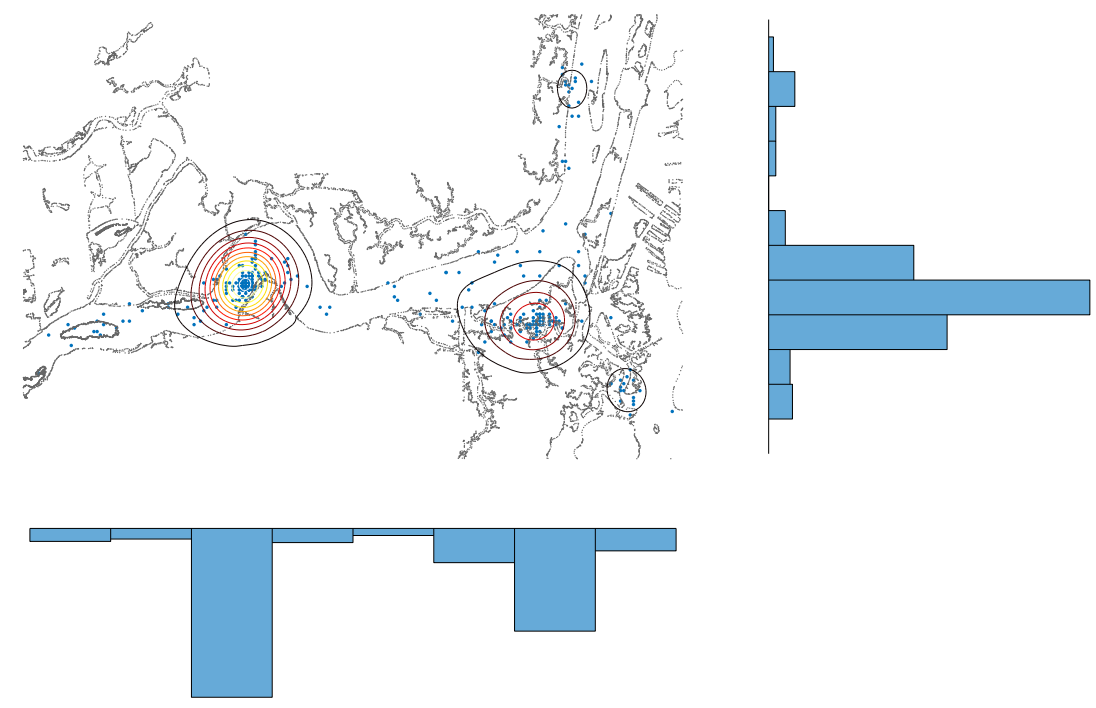

(a) Female (BRD1307)
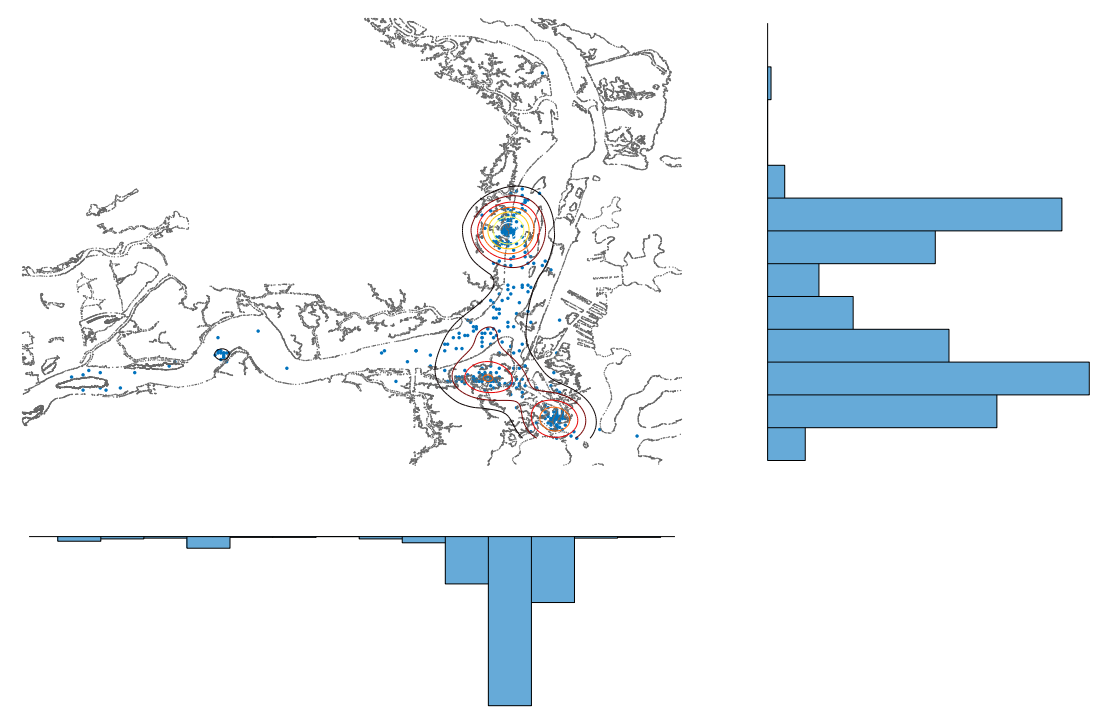

(b) Female (BRD1291)

Fig. 4. Representative female (BRD1307 - top; BRD1291 - bottom) otters' centers of use from a two-dimensional kernel density analysis. Histograms reflect the relative density of points on the axis of latitude and longitude. Estimated density increases from dark to light colors in contour lines. 

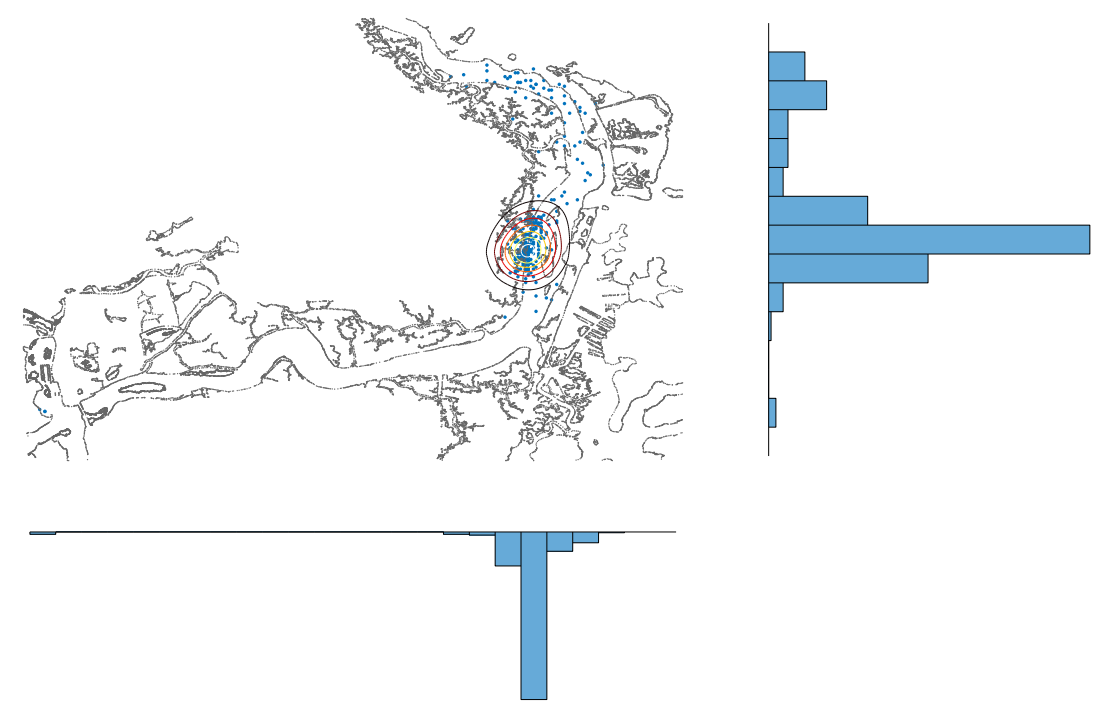

(a) Male (BRD1313)
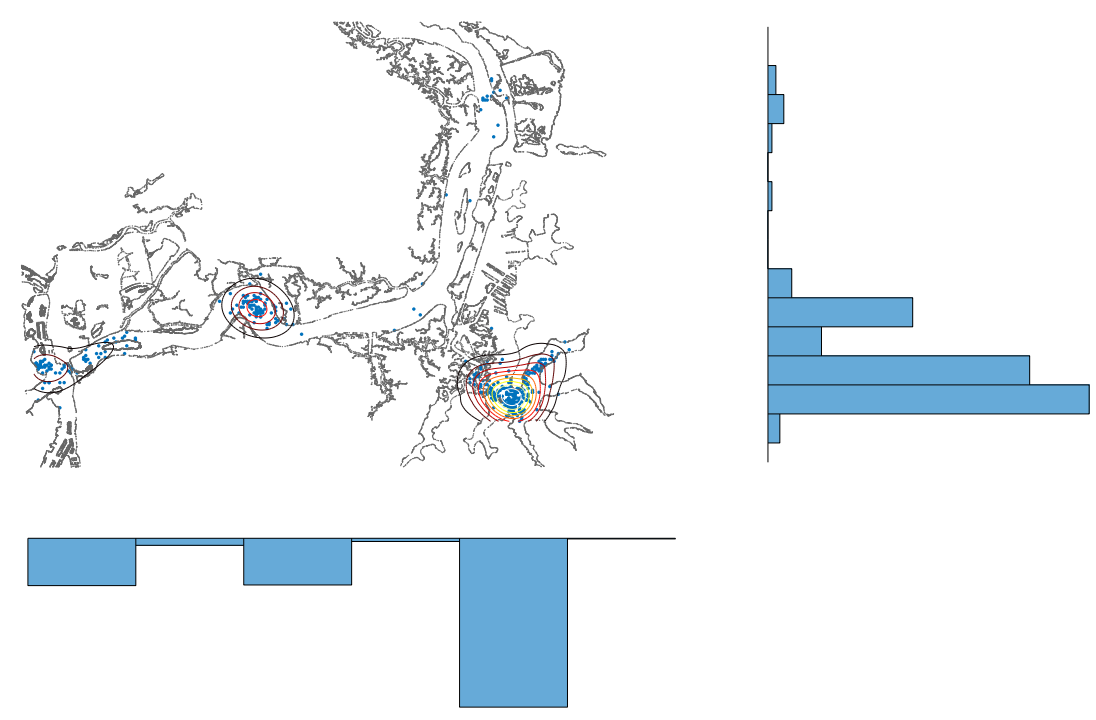

(b) Male (BRD1312)

Fig. 5. Representative male (BRD1313 - top; BRD1312 - bottom) otters' centers of use from a two-dimensional kernel density analysis. Histograms reflect the relative density of points on the axis of latitude and longitude. Estimated density increases from dark to light colors in contour lines. 
number of centers of use was significantly greater for females $(M=3)$ than males $(M=2)$ (Wilcoxon $Z=-2.37, p=0.0178)$.

Table 2. Percentage of males and females using between one and four centers of use.

\begin{tabular}{ccc}
\hline Number of Centers & \% Males $(n=9)$ & \% Females $(n=16)$ \\
\hline 1 & 33.3 & 12.5 \\
2 & 44.4 & 25.0 \\
3 & 22.2 & 56.3 \\
4 & 0.0 & 6.3 \\
\hline
\end{tabular}

To accurately compare male and female home ranges, I used areas from the $90 \%$ isopleth of the synoptic model's utilization distribution (Fig. 6). Average values for females were larger than territorial males, although not significantly (two-sample $t(6.58)=0.57, p=0.59)$. Average home range values for females, however, were significantly $(p<0.05)$ greater than all males combined (Table 3$)$. There was no linear correlation between an individual home range area and the sea otter's length $\left(r^{2}=0.053\right)$ nor between the home range area and average group size at point of resight $\left(r^{2}=0.054\right)$.

Table 3. Difference in home range areas $\left(\mathrm{km}^{2}\right)$ for males, territorial males and females, calculated from the $90 \%$ isolpeth of the synoptic utilization distribution (two-sample $t(21.14)=-2.90, p=0.0085)$.

\begin{tabular}{cccc}
\hline Statistic & Territorial Males $(n=4)$ & Males $(n=9)$ & Females $(n=16)$ \\
\hline Mean & 1.0034 & 0.9299 & 1.3907 \\
Variance & 0.1205 & 0.1109 & 0.2059 \\
\hline
\end{tabular}

In addition to the different numbers of centers of use, male and female otters ventured different distances along the path of the slough, measured along a polyline extending down the center of the main channel from mouth to inland end (Fig. 7). 


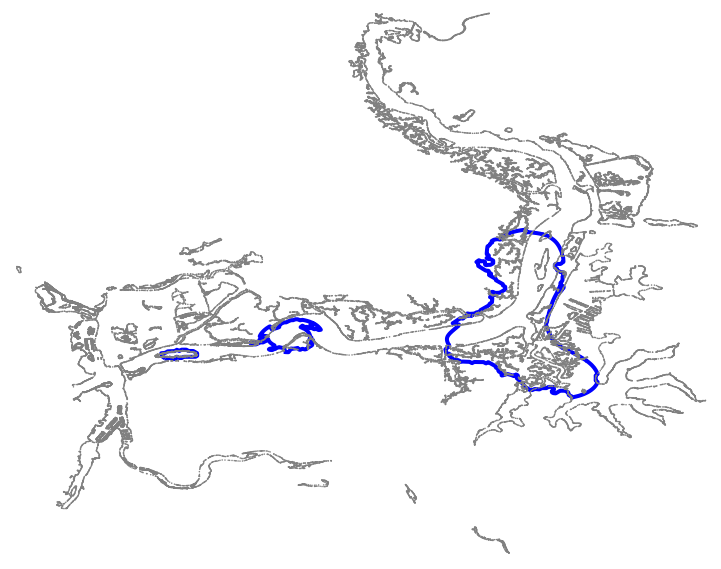

(a) Female (BRD1291). Home range area $=1.888 \mathrm{~km}^{2}$

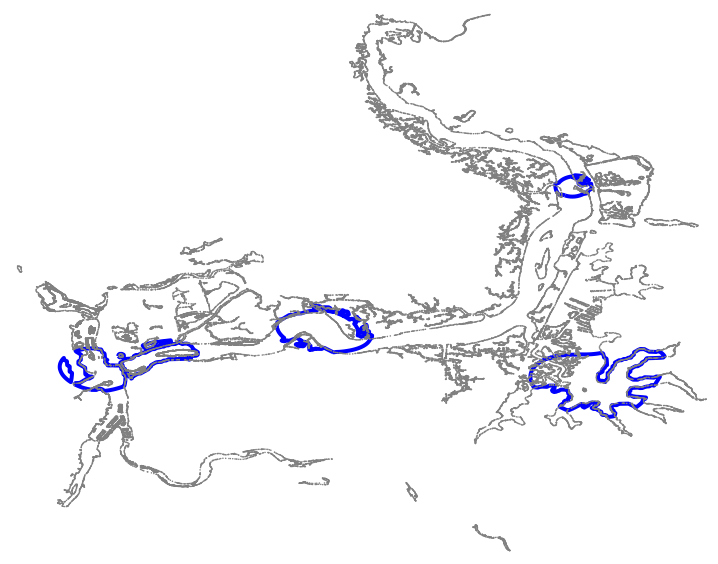

(b) Male (BRD1312). Home range area $=1.445 \mathrm{~km}^{2}$

Fig. 6. Representative female (BRD1291 - top) and male (BRD1312 - bottom) otters' centers of use from the $90 \%$ isopleth of the synoptic model's utilization distribution. Dark blue lines trace the $90 \%$ isopleth.

Males were found at the harbor mouth and up to $7 \mathrm{~km}$ from the ocean, whereas female ranges were between 1 and $6 \mathrm{~km}$ up the slough (Fig. 7). 


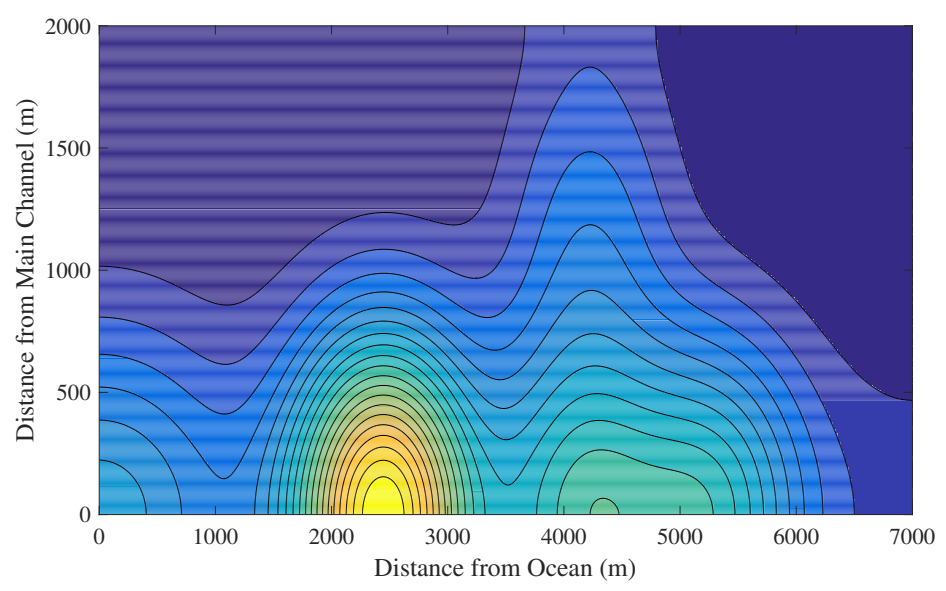

(a) Male

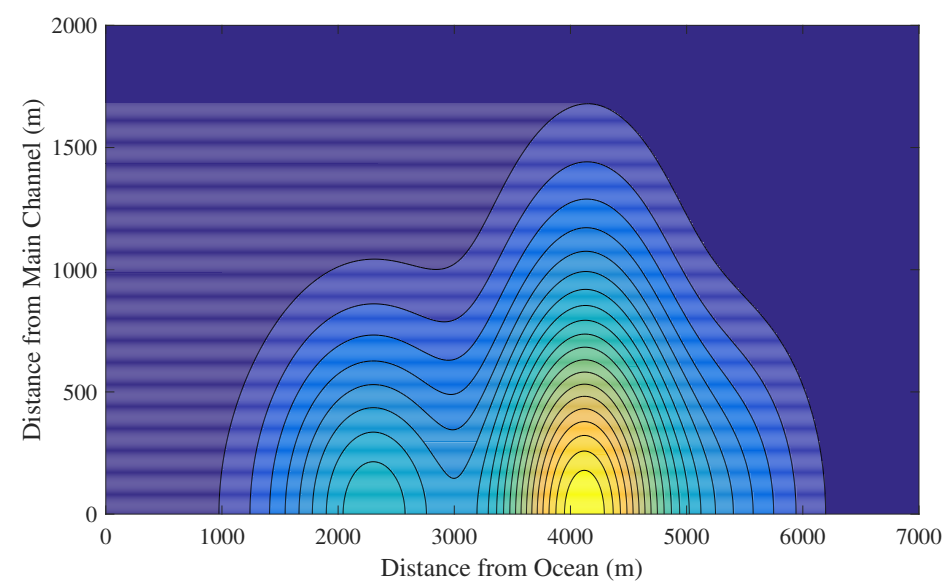

(b) Female

Fig. 7. Distribution of female and male sea otters between the mouth of the slough and the furthest inland point (Distance from Ocean) and outwards from the main channel (Distance from Main Channel). Density decreases from yellow to blue.

\section{Habitat Selection}

The hierarchical model described how sea otters of Elkhorn Slough used their space, taking into account habitat and distribution information. The probability surfaces for male and female otters (Fig. 8, 9) differed mostly for tidal creeks, with females using these areas more heavily than other areas (Fig. 9). Male and female otters both used eelgrass habitats heavily. However, male otters also were found in 
the harbor mouth and upper reaches of the slough (Fig. 8).

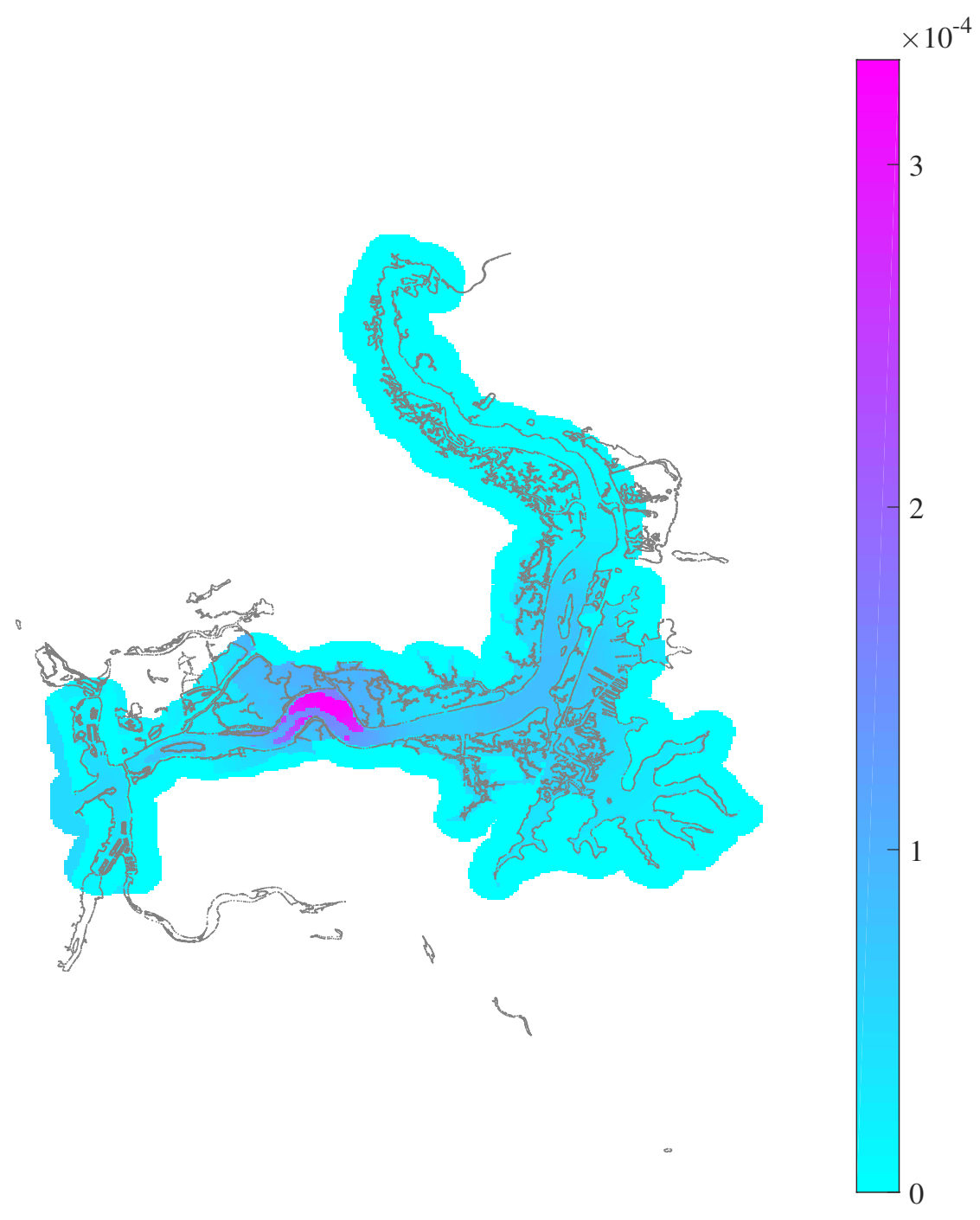

Fig. 8. Predicted distribution for male sea otters in Elkhorn Slough, with high relative density indicated by warm magenta, and low relative density indicated by turquoise.

The $\beta$ selection parameters that informed the utilization distributions in Fig. 8 and 9 provide additional insight into which habitats were most important in describing behavior-dependent use of Elkhorn Slough (Fig. 10, 11, 12). To achieve 


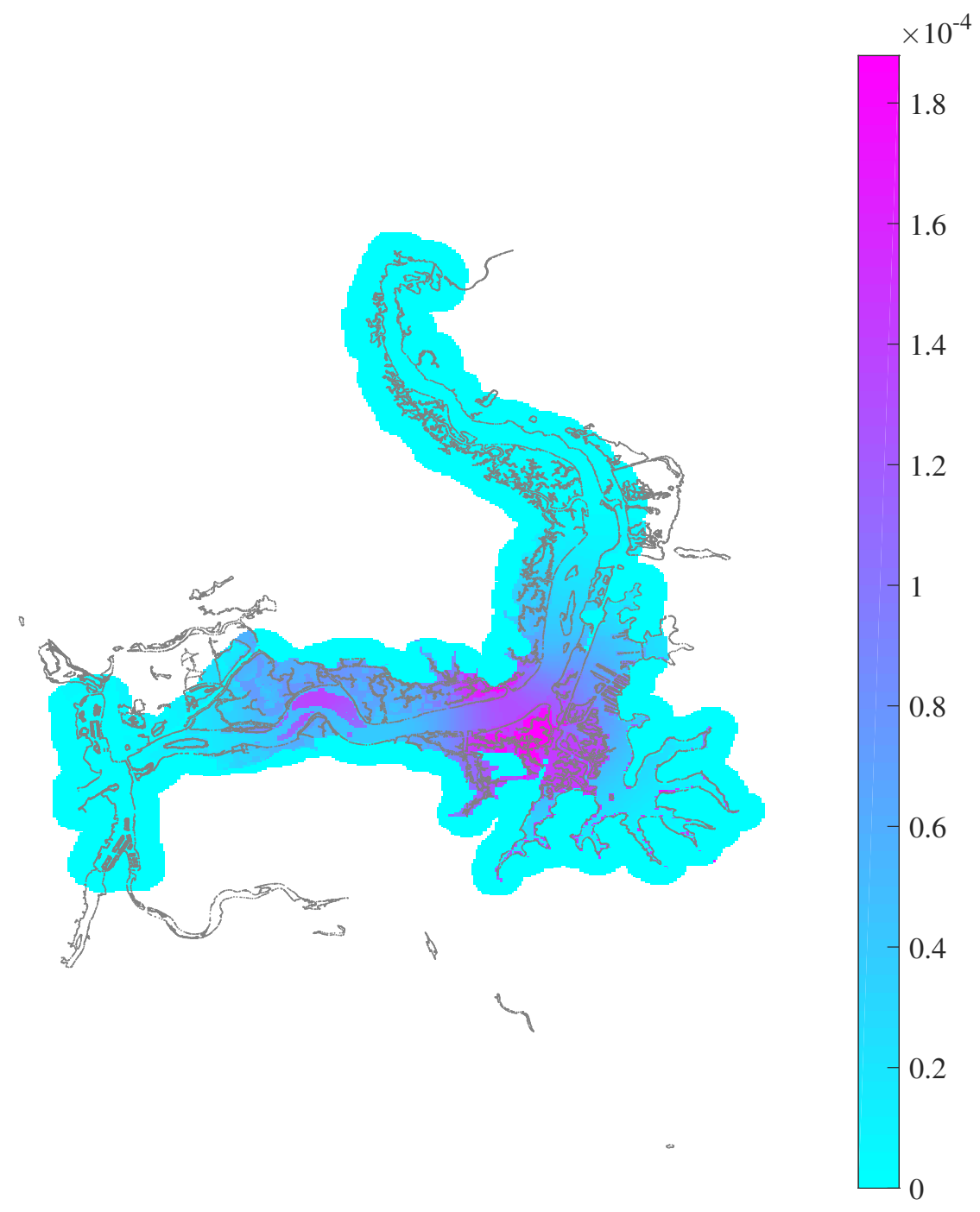

Fig. 9. Predicted distribution for female sea otters in Elkhorn Slough, with high relative density indicated by warm magenta, and low relative density indicated by turquoise.

enough resights for analysis, these behaviors were lumped into foraging and non-foraging (including resting, but also interacting, grooming, etc.) behaviors.

Habitats parameters were weighted significantly differently from the baseline main 
channel habitat when the probability density $95 \%$ confidence interval did not include 0. Male sea otters when foraging (Fig. 10b) were found in main channel habitat significantly more than saltmud, saltmarsh, and tidal creek habitats. When performing non-foraging behaviors (Fig. 10c), males were associated with eelgrass habitat more than main channel, and were less associated with saltmud and saltmarsh than the main channel.

Female otters also demonstrated a difference in predicted use of space depending upon their behaviors (Fig. 11). Like males, when foraging they were found in the main channel significantly more than in tidal creeks, saltmud, or saltmarsh (Fig. 11b). While resting and performing non-foraging behaviors they were strongly associated with eelgrass and tidal creeks, but not significantly with saltmud or saltmarsh compared with main channel (Fig. 11c).

Female otters also were modeled in groups depending on their reproductive status: with and without a pup. Females with and without pups were not further sub-divided into foraging and non-foraging behaviors, and the selection parameters for females overall were nearly identical to those for females with and without pups (Fig. 12). Females with and without pups were found more in eelgrass, and less in saltmud and saltmarsh, compared to main channel habitat.

The saltmarsh and saltmud habitat logit parameters, which were applied to weight selection of land habitats based on their distance to water, also converged in the synoptic space-use model. Land habitats were weighted over different ranges of distance from water, as seen in (Fig. 13), which indicated that sea otters used land features less as their distance from water increased. Male otters ventured further from water in saltmud habitats, but all sea otters were unlikely (less than $20 \%$ probability of use) to use saltmud habitats further than $200 \mathrm{~m}$ from water (Fig. 13). Saltmarsh habitats were used throughout their extent, with only a slight decrease in 
probability of use further from water. 


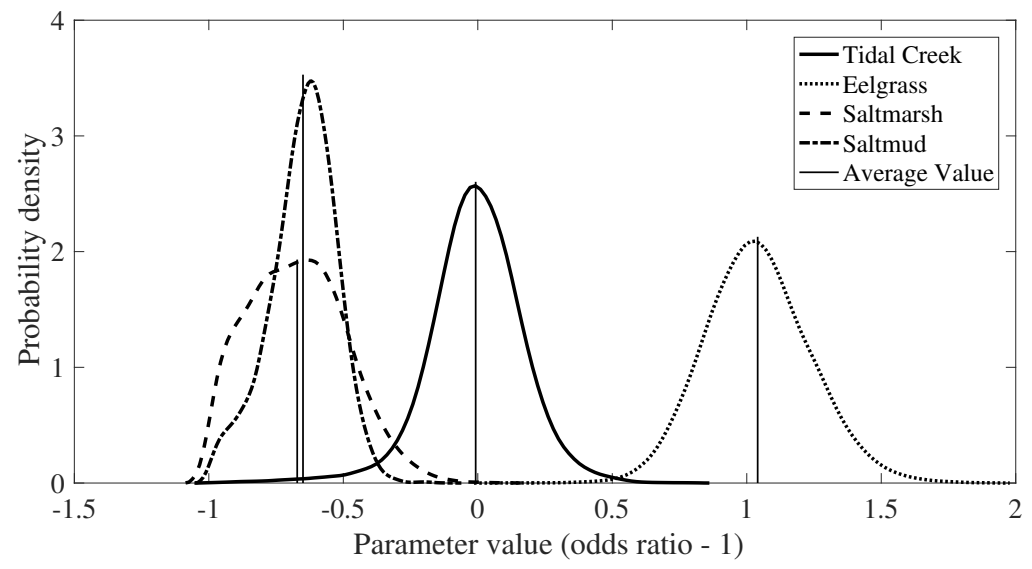

(a) Male: all behaviors. Main channel (0) is within the $95 \%$ CI for tidal creek.

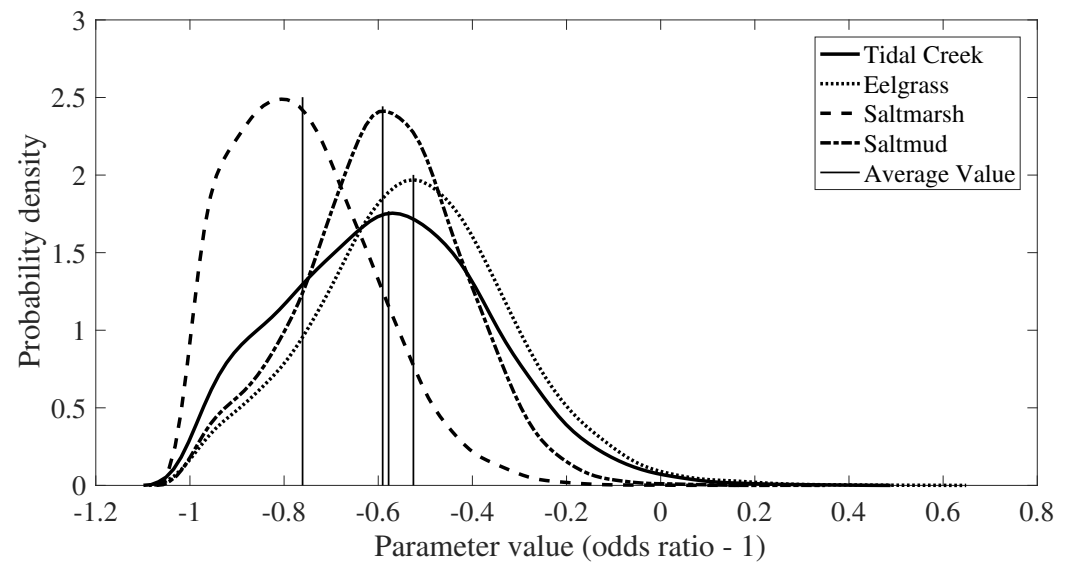

(b) Male: foraging. Main channel (0) is within the 95\% CI for eelgrass.

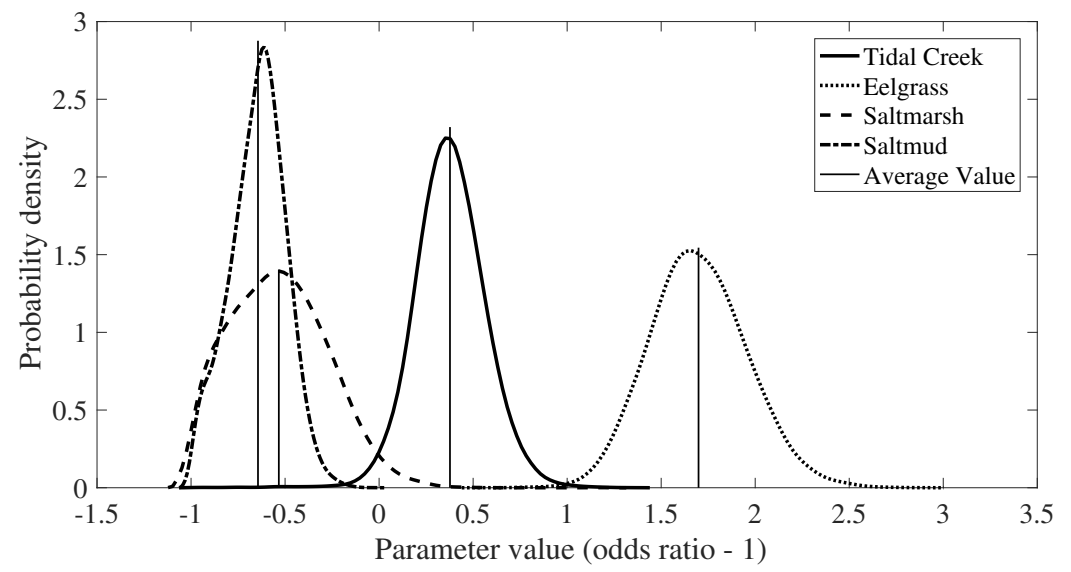

(c) Male: other. Main channel (0) is within the $95 \%$ CI for tidal creek.

Fig. 10. Average effect of model parameters for male otters relative to the main channel (0) habitat. Parameters are significantly different when the 95\% CI does not include 0 . The model was run three times for all behaviors, foraging, and other. 


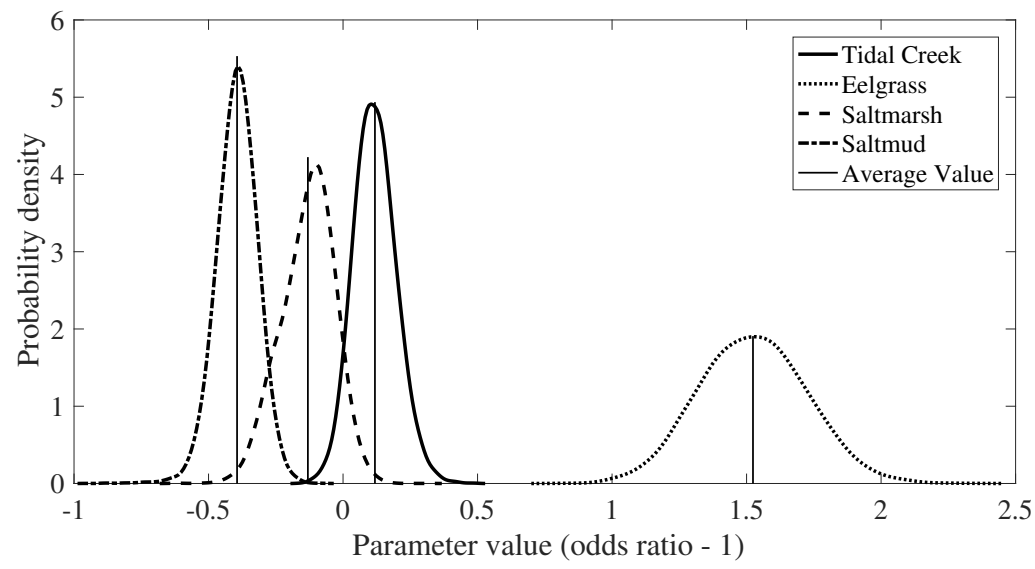

(a) Female: all behaviors. Main channel (0) is within the $95 \%$ CI for tidal creek.

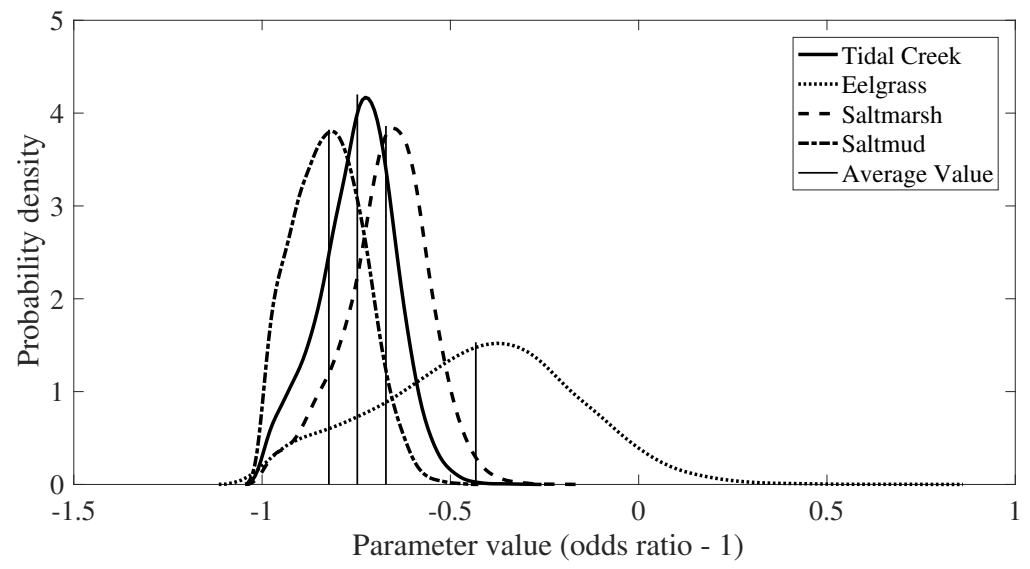

(b) Female: foraging. Main channel (0) is within the 95\% CI for eelgrass.

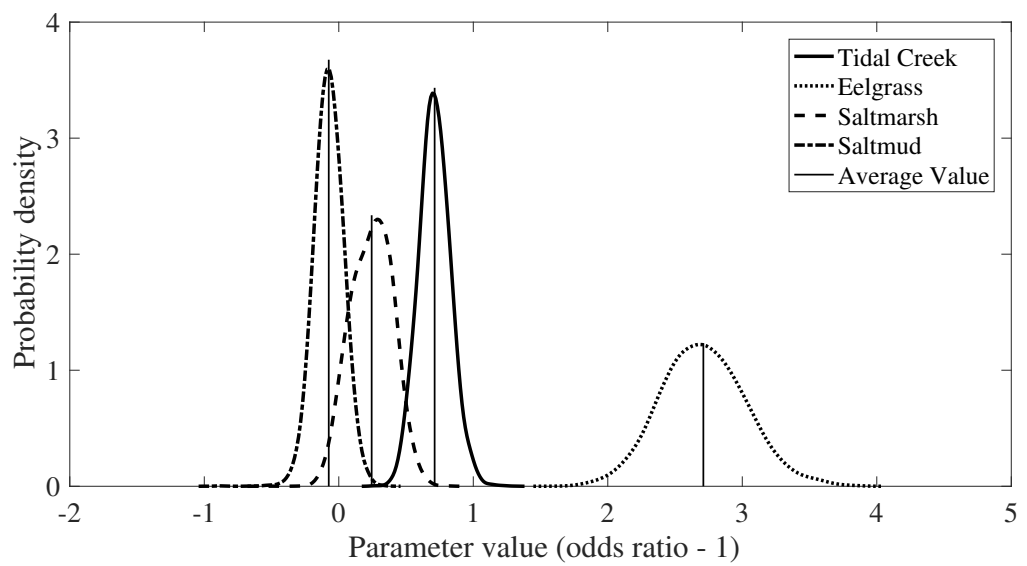

(c) Female: other. Main channel (0) is within the 95\% CI for saltmarsh and saltmud.

Fig. 11. Average effect of model parameters for female otters relative to the main channel (0) habitat. Parameters are significantly different when the 95\% CI does not include 0 . The model was run three times for all behaviors, foraging, and other. 


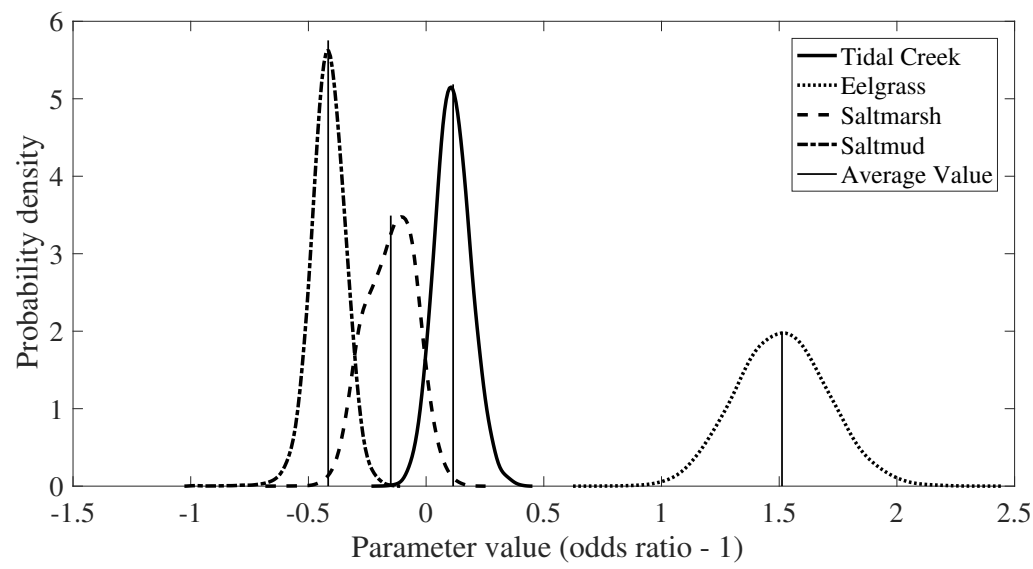

(a) Female: with pup. Main channel (0) is within the 95\% CI for tidal creek and saltmarsh.

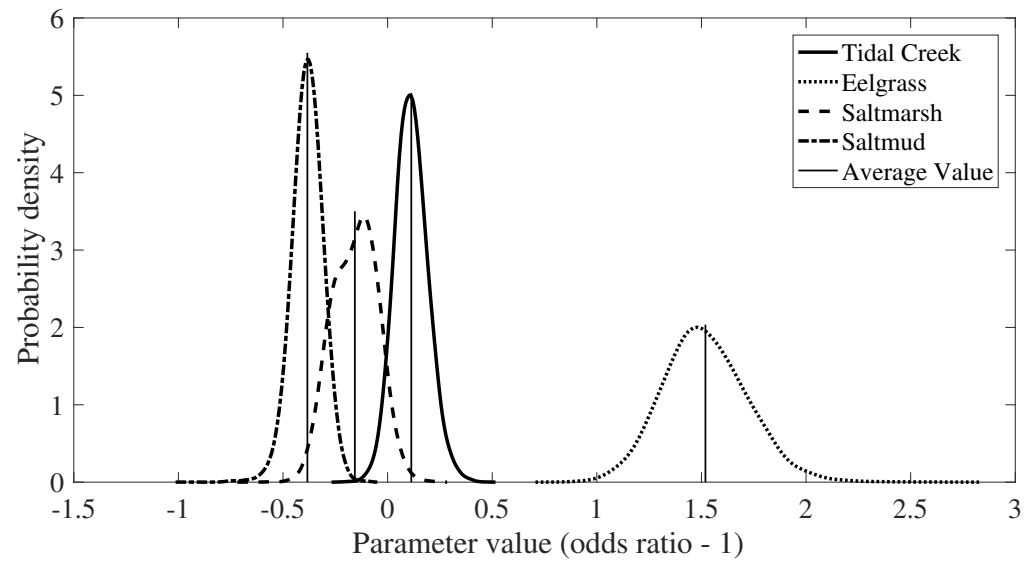

(b) Female: no pup. Main channel (0) is within the $95 \%$ CI for tidal creek.

Fig. 12. Average effect of model parameters for reproductive female otters relative to the main channel (0) habitat. Parameters are significantly different when the $95 \%$ CI does not include 0 . The model was run two times for females with and without pups. 


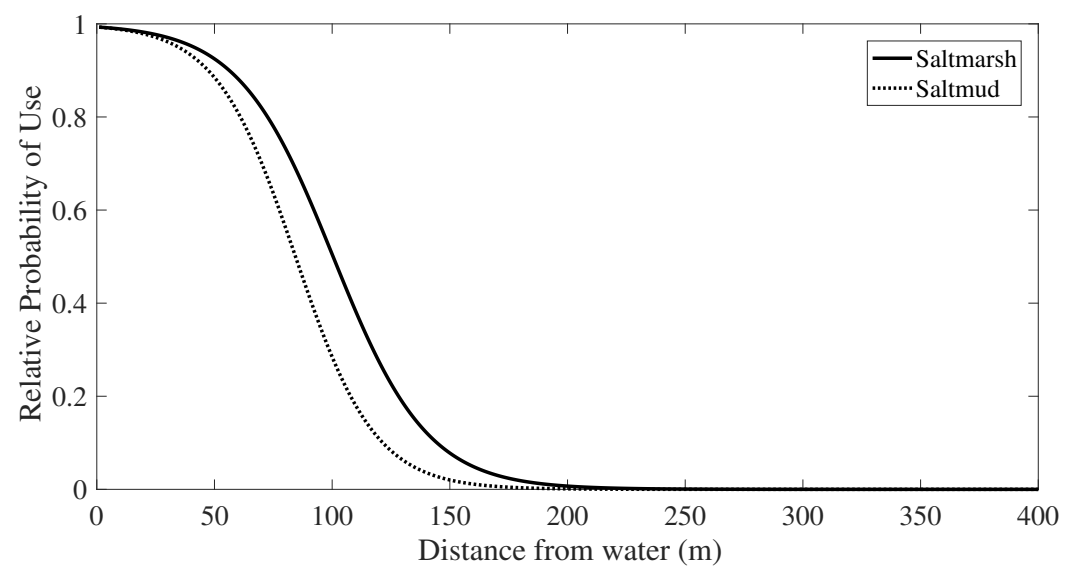

(a) Effect of distance to water for male sea otters

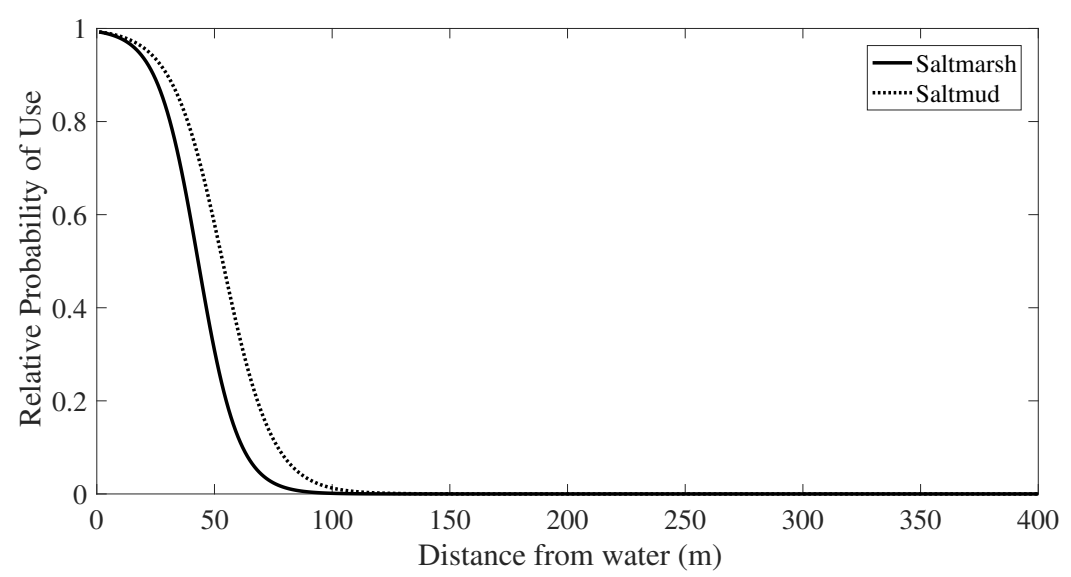

(b) Effect of distance to water for female sea otters

Fig. 13. Relative probability of use for saltmarsh and saltmud logit parameters, as a function of distance to water, for male and female otters. Sea otters used these land features less as their distance from water increased. 


\section{DISCUSSION}

Estuaries are important habitats for many species (Harvey and Connors 2002), and researchers recently have revealed that sea otters themselves are able to improve the habitats of estuarine systems (Hughes et al. 2013). Research that originally highlighted otters as keystone predators in a kelp forest ecosystem in the Aleutian Islands (Estes and Palmisano 1974) has been supported by more recent studies along the west coast (Estes and Duggins 1995; Estes et al. 1998; Wilmers et al. 2012; Markel and Shurin 2015). Sea otter consumption of herbivore prey in these ecosystems creates a trophic cascade that promotes the growth of macroalgae and indirectly influences animals that depend on the algae for habitat. The addition of sea otter predators also has improved the ecosystem health of eelgrass beds in Elkhorn Slough (Hughes et al. 2013). Otters consume crabs, which in turn increases mesograzers, decreases algal epiphytes, and promotes growth of eelgrass beds. If these animals are important in the recovery of estuarine systems in California, then understanding their habitat needs in estuaries will be of paramount importance.

It is unlikely that the knowledge that we have about soft-bottom habitats for sea otters in open-ocean locations can be used to predict estuarine habitat use. When Laidre et al. (2001) calculated the carrying capacity of a soft-sediment habitat (nearly 1 sea otter per $\mathrm{km}^{2}$ ), they allowed that the greater densities of sea otters in Elkhorn Slough (3-19 per $\mathrm{km}^{2}$ in 1995) indicated that the soft-sediment bottom of an estuary might be a different environment than the outer coast's soft-bottom habitats. The sheltered nature of an estuary and the large resting groups that it attracts may contribute to this difference in sea otter densities within an estuary. My analysis examined habitat parameters within the estuary to determine the important drivers of space use for the southern sea otter within this 
category of soft-sediment environment.

\section{Individual Home Ranges}

Species that must respond to changing seasons, life history status, or distribution of resources are inclined to use multiple, consistent centers of use depending on the circumstances (Burt 1943). For marine species, this often includes long-distance migrations between breeding and foraging grounds. Sea otters, however, change centers of use more often, but with less regularity and across smaller distances throughout the year (Loughlin 1980) than other marine species. Otters are subject to wind events (Kenyon 1969) and changing metabolic

requirements (Thometz et al. 2014) during pup rearing cycles, but do not respond to many traditional drivers for movement in space and changes in home range; sea otter prey and social groups to facilitate mating are located within the same geographic area.

The home ranges I calculated demonstrated a difference in the activities of sea otters in the slough compared with those on the outer coast. The home ranges of the sea otters in the Monterey Peninsula covered more area-11 km of the coastline for males and $12 \mathrm{~km}$ for females (Tarjan and Tinker 2016) — than the maximum distances that can be reached within the slough (less than $11 \mathrm{~km}$ ). In fact, sea otters in Elkhorn Slough did not use even the full extent of the slough's limited length. The difference in distances traveled within the slough and along the outer coast may be explained by the results by previous researchers conducting activity budgets within the slough. Sea otters in Elkhorn Slough had few reasons to travel long distances to find food. Historically, Elkhorn Slough had abundant prey (Feinholz 1998) and otters spent only 16-22\% of their time performing foraging activities (Wilkin 2003); in contrast, otters in resource-limited Monterey Bay spent 
between 35-50\% of their time searching for prey (Ralls and Siniff 1990). In the most recent studies, otters in Elkhorn Slough have spent approximately 37\% of their time foraging (USGS, unpublished data), whereas otters along the prey-limited outer coast spent between $42-45 \%$ of their time foraging (USGS, unpublished data). Because food is closer to safe resting areas in the slough than on the outer coast, individuals were not prompted to travel great distances to meet their needs during this study.

As predicted in my first hypothesis, the comparison of male and female home range areas indicated that males had smaller home ranges in Elkhorn Slough than females, although they traveled further between centers of use. Many of the male sea otters in Elkhorn Slough were territorial males, and those that were not consistently territorial displayed 'part-time' territorial behaviors during the study. Tarjan and Tinker (2016) recently calculated average home range areas for males $\left(10 \mathrm{~km}^{2}\right)$ and females $\left(7 \mathrm{~km}^{2}\right)$ along the Monterey Peninsula, which both exceeded the largest home range calculated for Elkhorn Slough $\left(1.9 \mathrm{~km}^{2}\right)$. The size of Elkhorn Slough male home ranges is likely smaller than females due to their need to defend their territory from encroaching males (Loughlin 1980; Jameson 1989; Ralls et al. 1996) within the confines of Elkhorn Slough. Additional differences between male and female otters were likely related to their differences in pup rearing responsibilities. Female sea otters' energetic investment while raising a dependent pup required increased metabolic requirements (Thometz et al. 2014) and associated increases in time spent foraging (Thometz et al. 2016). Females sacrificed optimum foraging behaviors - such as travel to a prey-abundant foraging location - in order to remain near shelter with their dependent pups (Thometz et al. 2016). During the course of the study, all 16 females raised dependent pups; meeting energetic requirements while rearing pups was the major driver of female home ranges 
throughout the study, placing females near sheltered tidal creeks.

\section{Habitat Selection}

The calculation of home ranges adds to the study of animal behavior by defining the space that an animal uses. By noting overlap between home ranges and nearby habitat, it is possible to indirectly infer an important resource. Similarly, from an individual's recorded behavior at certain locations, an inference could be made about why an animal uses that space. In answer to the second hypothesis of this study, the habitat variables combined with the behavior and status of individual sea otters provided context for the otter locations and insight into how sea otters make decisions about their use of space.

The synoptic model results combined information about space use patterns and individual behavior at the point of each resight, allowing for inferences about context-dependent habitat use. As I predicted in my third hypothesis, the model parameters indicated that male and female otters occured in protected eelgrass habitat for resting and non-foraging behaviors, with some use of tidal creeks. This pattern was similar to the use of kelp forests for resting areas on the outer coast (Jameson 1989; Ralls et al. 1996). However, females in Elkhorn Slough also used land habitat for non-foraging behaviors (e.g. resting), particularly in saltmarsh adjacent to (and within $200 \mathrm{~m}$ of) tidal creeks. During foraging efforts, both sexes vacated the safety of their sheltered habitats to enter the main channel, much like otters on the outer coast leave rafts for foraging (Loughlin 1980). In California and Alaska, sex-specific movement patterns in sea otters have been documented (Ralls et al. 1996; Tinker et al. 2008b), including greater dispersal distances for male otters. The different habitat preferences for males and females in Elkhorn Slough support these patterns, even in an estuarine environment. 
Future management of estuarine habitats should take into account the importance of eelgrass and tidal creeks as resting areas. Resting behaviors are easily disturbed yet are key to the survival of this energetically demanding species, especially in resource-limited populations. From studies on oiled sea otters, it has been determined that sea otters consistently lose heat while resting, but at a slow pace due to decreased metabolic rates (Costa and Kooyman 1982). Any activity that interrupted resting metabolic rates caused raised energy expenditure (Yeates et al. 2007; Thometz et al. 2014). Kayak activity and sea otter disturbances in Elkhorn Slough have increased during the past 15 years (Team Ocean, unpublished data). If kayak disturbance must occur somewhere, disturbance of otters in the open channel where they are likely to be foraging - rather than resting - would be preferable to similar disturbances near resting sea otters in eelgrass beds, tidal creeks, or saltmarsh. Disturbance of sea otter resting behaviors already is evident in the harbor mouth where there is regular human activity. Maldini et al. (2012) recorded the pattern of sea otter haul out behavior in the harbor mouth, which follows the inverse of the pattern of human activity: increased use of land in the evenings and seasons with lower tourist traffic. Maldini et al. also found that environmental variables that increased metabolic rate - such as lower air and water temperature - were significantly correlated with more sea otters on land (Maldini et al. 2012). If human recreational activities are allowed in and around Elkhorn Slough's inland tidal creeks and eelgrass beds, these key resting areas could similarly become restricted to only infrequent and carefully timed resting behaviors. This will become especially important as sea otters in Elkhorn Slough approach their carrying capacity.

Although the current distribution of animals does not extend into the furthest inland reaches of the estuary, sea otters have moved further inland from the 
entrance of the slough just during the course of this study. From the model's habitat weights based on the current distribution, I predict that as sea otters move further up the slough they will use the tidal creeks, main channel, and eelgrass beds in those northern reaches for key resting and foraging activities. Barring confounding factors, such as decreasing prey abundance as one moves farther from the ocean, sea otters may eventually use the tidal creeks and mid-channel open water at Elkhorn Slough's northernmost end with the same frequency as the lower reaches.

The logit parameters included in the hierarchical analysis provided predictive power to estimate where sea otters will be found near water when they are hauled out on land. These data indicated estuarine saltmarsh and saltmud habitats were important for sea otters to at least $50 \mathrm{~m}$ from the water's edge, and as much as 200 m. Maldini et al. (2012) documented that sea otters in Elkhorn Slough come ashore frequently; this behavior appears to be related to ambient conditions, as has been reported in northern sea otter populations (Kenyon 1969). Early studies in Elkhorn Slough noted that haul out behavior was not common (Jolly 1997; Harvey and Connors 2002; Wilkin 2003), but these studies took place before there were resident females with pups in Elkhorn Slough, when the population was primarily transient males. Sea otters are the most recently adapted marine mammals, having evolved aquatic adaptations only 1-3 million years ago (Berta et al. 2006); therefore it is unsurprising that we have documented more land association as we study these animals in a protected estuarine environment. Sea otters in Elkhorn Slough are seen to move, groom, and forage in mud and marsh along the boundaries of their marine environment. These results will be important to consider as managers plan for sea otters in estuarine environments. The range of significant land habitat within Elkhorn Slough can be used by land managers to ensure that the estuary is fully available for on-land resting behaviors by sea otters. 
The current parameterization of the synoptic model provided insights about sea otter habitat use in an estuary. As more habitat data become available, however, this model can be revised to explore more detailed patterns of habitat selection. Depth is unlikely to affect habitat use in the slough, as sea otters limit their dives to less than $100 \mathrm{~m}$, which is well below any depths in this estuary. At present the most recent and complete bathymetric survey was more than five years ago. Rapid erosion and depth changes due to the high-energy tidal nature of the slough make older measurements likely to be inaccurate at present. To test if depth affects sea otter habitat use in an estuary by including it as a parameter in this model, more recent surveys would be needed. Prey distribution is another parameter that could not be included at this stage of the Elkhorn Slough otter study. USGS is in the final stages of a study to survey infaunal and epifaunal invertebrates in the slough; when combined with earlier surveys by Kvitek (1988) these comprehensive surveys will provide insight into how prey abundance and distribution has changed in response to sea otter recolonization. These data will also allow for inclusion of prey distribution into future habitat selection models. At the time of Kvitek's surveys, it was thought that the deep-burrowing bivalve prey were able to find refuge from foraging sea otters, therefore, were resistant to severe impact by sea otters; however the rate at which sea otters consume prey makes any previous estimates of prey size and distribution unlikely to be accurate (Kvitek et al. 1992). As further information about the benthic communities of Elkhorn Slough are collected, these variables can be incorporated into the habitat layers of this predictive model to compare prey or depth influences with habitat parameters already included. If the importance of such parameters can be demonstrated in this estuary, they also might be taken into account by resource managers as they contemplate eventual colonization of sea otters into other estuaries. 
Although the Elkhorn Slough otter population is small relative to the population in Monterey Bay, use of this estuarine environment is indicative of potential sea otter activity within estuaries that may be colonized in the future. Transplanting rehabilitated animals to these new locations, rather than back into the food-limited range center (Tinker et al. 2008a), could encourage re-expansion into the southern sea otter's historic ranges as it encouraged expansion into Elkhorn Slough. For example, the San Francisco Bay estuary contains habitats similar to Elkhorn Slough, and it is within the historic range of the southern sea otter. Today, beds of eelgrass of varying size exist around the edges of the bay (California State Coastal Conservancy and Ocean Protection Council et al. 2010). In addition, intertidal mudflats and shellfish beds are major features of the subtidal and intertidal habitats of the San Francisco Bay estuary (California State Coastal Conservancy and Ocean Protection Council et al. 2010). Restoration efforts are underway in all of these habitat features. When sea otters re-occupied Elkhorn Slough, these habitat types experienced an increase in ecosystem health. In addition to encouraging the recovery of the southern sea otter, a return of sea otters to the San Francisco Bay estuary may also benefit the estuarine habitats themselves. 


\section{REFERENCES}

Benson JF, Sikich JA, Riley SPD. 2016. Individual and population level resource selection patterns of mountain lions preying on mule deer along an urban-wildland gradient. Plos One 11(7):1-16.

Berta A, Sumich JL, Kovacs KM. 2006. Marine Mammals: Evolutionary Biology. 2nd. San Diego: Academic Press.

Burt WH. 1943. Territoriality and home range concepts as applied to mammals. Journal of Mammalogy 24(3):346-352.

Caffrey J, Broenkow W. 2002. Hydrography. In: Changes in a California Estuary: A Profile of Elkhorn Slough. Ed. by Caffrey JM, Brown M, Tyler WB, Silberstein MA. Moss Landing: Elkhorn Slough Foundation. Chap. 4:29-42.

California Senate. 1965. Third Progress Report to the Legislature, 1965 Regular Session. Senate Permanent Factfinding Committee on Natural Resources. Tech. rep. Sacramento: California Legislature:129-144.

California State Coastal Conservancy and Ocean Protection Council, NOAA, San Francisco Bay Conservation and Development Commission, San Francisco Estuary Partnership. 2010. San Francisco Bay subtidal habitat goals report: conservation planning for the submerged areas of the bay. Tech. rep. Oakland: State Coastal Conservancy:147-161.

Costa DP, Kooyman GL. 1982. Oxygen consumption, thermoregulation, and the effect of fur oiling and washing on the sea otter, Enhydra lutris. Canadian Journal of Zoology 60:2761-2767.

Costa DP. 1982. Energy, Nitrogen, and Electrolyte Flux and Sea Water Drinking in the Sea Otter Enhydra lutris. Physiological Zoology 55(1):35-44.

Costa DP, Kooyman GL. 1984. Contribution of specific dynamic action to heat balance and thermoregulation in the sea otter Enhydra lutris. Physiological Zoology 57(2):199-203.

Drake EM, Cypher BL, Ralls K, Perrine JD, White R, Coonan TJ. 2015. Home-range size and habitat selection by male island foxes (Urocyon littoralis) in a low-density population. The Southwestern Naturalist 60(2-3):247-255.

Estes JA. 1990. Indices used to assess status of sea otter populations. Journal of Wildlife Management 54(2):270-272. 
Estes JA, Duggins DO. 1995. Sea otters and kelp forests in Alaska: generality and variation in a community ecological paradigm. Ecological Monographs 65(1):75-100.

Estes JA, Palmisano JF. 1974. Sea otters: their role in structuring nearshore communities. Science 185(4156):1058-1060.

Estes JA, Tinker MT, Williams TM, Doak DF. 1998. Killer whale predation on sea otters linking oceanic and nearshore ecosystems. Science 282(5388):473-476.

Estes JA, Underwood KE, Karmann MJ. 1986. Activity-time budgets of sea otters in California. The Journal of Wildlife Management 50(4):626-636.

Feinholz DM. 1998. Abundance, distribution, and behavior of the southern sea otter (Enhydra lutris nereis) in a California estuary. Aquatic Mammals 24(2):105-116.

Harvey J, Connors S. 2002. Birds and Mammals. In: Changes in a California Estuary: A Profile of Elkhorn Slough. Ed. by Caffrey J, Brown M, Tyler B, Silberstein M. Moss Landing: Elkhorn Slough Foundation. Chap. 11:188-212.

Horne JS, Garton EO, Rachlow JL. 2008. A synoptic model of animal space use: simultaneous estimation of home range, habitat selection, and inter/intra-specific relationships. Ecological Modeling 214:338-348.

Hughes BB, Eby R, Van Dyke E, Tinker MT, Marks CI, Johnson KS, Wasson K. 2013. Recovery of a top predator mediates negative eutrophic effects on seagrass. Proceedings of the National Academy of Sciences 110(38):15313-15318.

Jameson RJ. 1989. Movements, home range, and territories of male sea otters off central California. Marine Mammal Science 5(2):159-172.

Jolly J. 1997. Foraging ecology of the sea otter, Enhydra lutris, in a soft-sediment community. M.S. University of California Santa Cruz:1-61.

Jones T, Culleton B, Larson S, Mellinger S, Porcasi J. 2011. Toward a Prehistory of the Southern Sea Otter (Enhydra lutris nereis). In: Human impacts on seals, sea lions and sea otters: integrating archaeology and ecology in the northeast Pacific. Ed. by Braje T, Rick T. Berkley: University of California Press. Chap. 11.

Kenyon KW. 1969. The sea otter in the Eastern Pacific Ocean. North American Fauna 68:1-352. 
Kieckhefer T, Cassidy J, Hoffman J, Reif S, Maldini D. 2004. Rise and Fall of Southern Sea Otters (Enhydra lutris nereis) in Elkhorn Slough, California, 1994-2003. In: Society for Marine Mammalogy Conference.

Kvitek RG, Fukayama AK, Anderson BS, Grimm BK. 1988. Sea otter foraging on deep-burrowing bivalves in a California coastal lagoon. Marine Biology 98:157-167.

Kvitek RG, Oliver JS, DeGange A, Anderson B. 1992. Changes in Alaskan soft-bottom prey communities along a gradient in sea otter predation. Ecological Society of America 73(2):413-428.

Laidre KL, Jameson RJ, DeMaster DP. 2001. An estimation of carrying capacity for sea otters along the California coast. Marine Mammal Science 17(2):294-309.

Loughlin TR. 1980. Home range and territoriality of sea otters near Monterey, California. The Journal of Wildlife Management 44(3):576-582.

Maldini D, Scoles R, Eby R, Cotter M, Rankin RW. 2012. Patterns of sea otter haul-out behavior in a california tidal estuary in relation to environmental variables. Northwestern Naturalist 93:67-78.

Maldini D, Ward C, Cecchetti A, Riggin J. 2010. Southern sea otter diet in a soft sediment community. Journal of Marine Animals and Their Ecology 3(1):27-36.

Markel R, Shurin J. 2015. Indirect effects of sea otters on rockfish (Sebastes spp.) in giant kelp forests. Ecology 96(11):2877-2890.

Ralls K, Eagle TC, Siniff DB. 1996. Movement and spatial use patterns of California sea otters. Canadian Journal of Zoology 74:1841-1849.

Ralls K, Siniff DB. 1990. Time budgets and activity patterns in California sea otters. The Journal of Wildlife Management 54(2):251-259.

Ralls K, Siniff DB, Williams TD, Kuechle V. 1989. An intraperitoneal radio transmitter for sea otters. Marine Mammal Science 5(4):376-381.

Tarjan L, Tinker M. 2016. Permissible Home Range Estimation (PHRE) in complex habitats: a new general algorithm and an evaluation for sea otters (Enhydra lutris). PLOS ONE 11(3):1-20.

Thometz NM, Staedler MM, Tomoleoni JA, Bodkin JL, Bentall GB, Tinker MT. 2016. Trade-offs between energy maximization and parental care in a central place forager, the sea otter. Behavioral Ecology Online:1-15. 
Thometz NM, Tinker MT, Staedler MM, Mayer KA, Williams TM. 2014. Energetic demands of immature sea otters from birth to weaning: implications for maternal costs, reproductive behavior and population-level trends. The Journal of Experimental Biology 217(12):2053-61.

Tinker M, Bentall G, Estes JA. 2008a. Food limitation leads to behavioral diversification and dietary specialization in sea otters. Proceedings of the National Academy of Sciences 105(2):560-565.

Tinker M, Doak DF, Estes JA. 2008b. Using demography and movement behavior to predict range expansion of the southern sea otter. Ecological Applications 18(7):1781-1794.

Tinker M, Doak DF, Estes JA, Hatfield BB, Staedler MM, Bodkin JL. 2006. Incorporating diverse data and realistic complexity into demographic estimation procedures for sea otters. Ecological Applications 16(6):2293-2312.

Tinker M, Tomoleoni J, Weitzman B, Staedler M, Murray M, Miller M, Burgess T, Bowen L, Miles K, Thometz N, Tarjan L, Golson E, Batac F, Dodd E, Berberich E, Kunz J, Bentall G, Fujii J, Nicholson T, Newsome S, Melli A, LaRoche N, MacCormick H, Johnson A, Henkel L, Kreuder-Johnson C, Conrad P. 2013. Sea otter population biology at Big Sur and Monterey California: investigating the consequences of resource abundance and anthropogenic stressors for sea otter recovery. Tech. rep.:243.

U.S. Fish and Wildlife Service. 2003. Final Revised Recovery Plan for the Southern Sea Otter (Enhydra lutris nereis). Tech. rep. Portland, Oregon:i +165 .

USFW. 2012. Endangered and threatened wildlife and plants; termination of the southern sea otter translocation program. Tech. rep. 244:1-33.

USFW. 2015. Southern sea otter (Enhydra lutris nereis) 5-year review: summary and evaluation. Tech. rep.:42.

Wilkin SM. 2003. Nocturnal foraging ecology and activity budget of the sea otter (Enhydra lutris) in Elkhorn Slough, California. M.S. San Francisco State University:56.

Wilmers CC, Estes JA, Edwards M, Laidre KL, Konar B. 2012. Do trophic cascades affect the storage and flux of atmospheric carbon? An analysis of sea otters and kelp forests. Frontiers in Ecology and the Environment 10(8):409-415.

Woolfolk A. 2005. Elkhorn Slough Tidal Wetland Plan: Evolution of Elkhorn Slough and Associated Wetlands 20,000 years before present (ybp) to 1880 A.D. 
Tech. rep. Watsonville: Elkhorn Slough National Estuarine Research Reserve:1-10.

Yeates LC, Williams TM, Fink TL. 2007. Diving and foraging energetics of the smallest marine mammal, the sea otter (Enhydra lutris). The Journal of Experimental Biology 210:1960-70. 